\title{
The oncogenic neurotrophin receptor tropomyosin-related kinase variant, TrkAll
}

\author{
Antonietta Rosella Farina, Lucia Cappabianca, Pierdomenico Ruggeri, Luciana Gneo, Cristina Pellegrini, \\ Maria-Concetta Fargnoli and Andrew Reay Mackay ${ }^{*}$ (i)
}

\begin{abstract}
Oncogenes derived from the neurotrophin receptor tropomyosin-related kinase TrkA act as drivers in sub-populations of a wide-range of human cancers. This, combined with a recent report that both adult and childhood cancers driven by novel oncogenic TrkA chimeric-fusions exhibit profound, long-lived therapeutic responses to the Trk inhibitor Larotrectinib, highlights the need to improve clinical detection of TrkA oncogene-driven cancers in order to maximise this novel therapeutic potential. Cancers potentially driven by TrkA oncogenes include a proportion of paediatric neuroblastomas (NBs) that express the alternative TrkA splice variant TrkAlll, which exhibits exon 6, 7 and 9 skipping and oncogenic-activity that depends upon deletion of the extracellular D4 Ig-like domain. In contrast to fully spliced TrkA, which exhibits tumour suppressor activity in NB and associates with good prognosis, TrkAlll associates with advanced stage metastatic disease, post therapeutic relapse and worse prognosis, induces malignant transformation of NIH-3T3 cells and exhibits oncogenic activity in NB models. TrkAll induction in NB cells is stress-regulated by conditions that mimic hypoxia or perturbate the ER with potential to change TrkA tumour-suppressing signals into oncogenic TrkAlll signals within the stressful tumour microenvironment. In contrast to cell surface TrkA, TrkAll re-localises to intracellular pre-Golgi membranes, centrosomes and mitochondria, within which it exhibits spontaneous ligand-independent activation, triggering a variety of mechanisms that promote tumorigenicity and malignant behaviour, which impact the majority of cancer hallmarks. In this review, we present updates on TrkAll detection and association with human malignancies, the multiple ways TrkAlll exerts oncogenic activity and potential therapeutic approaches for TrkAlll expressing cancers, with particular reference to NB.
\end{abstract}

Keywords: TrkAlll, Alternative splicing, Neuroblastoma, Oncogenic signaling, Unfolded protein response, Warburg effect, Hallmarks of cancer, Therapeutic approaches

\section{Background}

The neurotrophin receptor tropomyosin-related kinase A (TrkA) regulates responses to the neurotrophins NGF and NT3 in a wide variety of normal tissues and is critical for normal development and function of both nervous and immunological systems [1, 2].

The first human TrkA-derived oncogene, Trk-oncogene, was identified in colon cancer as a novel chimeric fusion between truncated tropomyosin and protein tyrosine kinase sequence [3]. This preceded TrkA proto-oncogene characterisation as an NGF receptor [4] and the identification of numerous TrkA-derived oncogenes in a wide-range of human cancers. TrkA oncogenes are now considered

\footnotetext{
* Correspondence: andrewreay.mackay@univaq.it

Department of Applied Clinical and Biotechnological Sciences, University of L'Aquila, L'Aquila, Italy
}

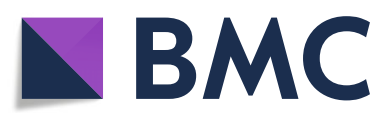

(c) The Author(s). 2018 Open Access This article is distributed under the terms of the Creative Commons Attribution 4.0 International License (http://creativecommons.org/licenses/by/4.0/), which permits unrestricted use, distribution, and reproduction in any medium, provided you give appropriate credit to the original author(s) and the source, provide a link to the Creative Commons license, and indicate if changes were made. The Creative Commons Public Domain Dedication waiver (http://creativecommons.org/publicdomain/zero/1.0/) applies to the data made available in this article, unless otherwise stated. man cancers and, therefore, represent important therapeutic targets [3-18]. Recently, adult and childhood cancers driven by novel chimeric TrkA-fusion oncogenes have been reported to exhibit profound and long-lived therapeutic responses to the Trk inhibitor Larotrectinib [18], highlighting a need to improve clinical detection of cancers driven by activated TrkA oncogenes in order to take full advantage of novel Trk-inhibitory therapies [13-18].

Cancers potentially driven by TrkA oncogenes include paediatric neuroblastomas (NBs), a significant proportion of which express the oncogenic alternative TrkA splice variant, TrkAIII. TrkAIII exhibits exon 6-7 skipping and is subject to spontaneous ligand-independent intracellular activation, dependent upon deletion of the 
extracellular receptor D4 Ig-like domain, encoded within exons 6 and 7, which acts as a spontaneous-activation prevention domain [19]. In contrast to fully spliced TrkA, which exhibits tumour suppressor function in NB and associates with better prognosis, TrkAIII expression associates with advanced stage metastatic disease, post therapeutic relapse and poor prognosis. TrkAIII also induces malignant transformation of NIH3T3 cells and exhibits oncogenic activity in NB models [1, 19-22], confirming its oncogenic nature and suggesting that patients with tumours that express TrkAIII may benefit from Trk-inhibitory therapy.

\section{TrkAlll detection and association with human malignancies}

TrkAIII was originally detected as an unexpected TrkA RT-PCR product in primary human NBs and full length TrkAIII cDNA was subsequently cloned from human SH-SY5Y NB cells. TrkAIII represents a novel alternative $\operatorname{Trk} A$ splice variant that exhibits skipping of exons 6, 7 and 9, resulting in deletion of the receptor extracellular D4 Ig-like domain and several N-glycosylation sites (Fig. 1) [19]. In human NBs, TrkAIII expression associates with advanced-stage metastatic disease, post-therapeutic relapse and worse prognosis, whereas expression of fully spliced TrkA associates with better prognosis, spontaneous regression and enhanced event-free survival $[1,19-22]$. In addition to NBs, human glioblastoma multiforme tumours also express TrkAIII, including an EGFR and EGFRvIII negative subpopulation, suggesting that TrkAIII represents a potential oncogenic alternative to EGFR and EGFRvIII oncogenes in this tumour type [23]. Recently, we have also detected alternative TrkAIII splicing in cutaneous melanomas, with sequence-verified evidence for exclusive TrkAIII expression in individual primary and metastatic tumours. This novel, not previously published data, supports a potential role for TrkAIII in melanoma pathogenesis and progression (manuscript in preparation) (Fig. 2). TrkAIII expression in melanoma may help to explain the reported association between malignant melanoma and intracellular TrkA activation, considering that the expression of fully spliced TrkA exhibits paradoxical tumour suppressing activity in melanoma cells [24]. TrkAIII expression in melanoma, furthermore, may also combine with $\operatorname{Trk} A$ gene amplification, reported in up to $50 \%$ of tumours [25]. In tumour cell lines, both constitutive and stress-regulated TrkAIII expression has been detected in numerous NB cell lines, PC-3 prostate cancer cells, PC-12 pheochromocytoma cells, U251 glioma cells and Jurkat T cell leukaemia cells [19, 22, 26, 27].

Routine RT-PCR detection of fully spliced TrkA and alternatively spliced TrkAIII, utilising exon 8 and exon 5 primers sets [19], has been improved by adding TrkAIII-specific and exons 6/7-specific primer sets that discriminates between TrkAIII and TrkA cDNAs containing exon $6 / 7$ sequence. The TrkAIII-specific primer set: forward primer 5'-TGC gCA ATG CCA GCT GTG TaC CgG tCa-3' (novel exon 5-8 splice junction), bears point mutations (lower case) and reverse primer 5'-AGT ATT GTG GGT TCT CGA TGA TGT-3' (exon 12 ) that abrogate amplification of exons 6/7-containing TrkA cDNAs, without compromising TrkAIII cDNA amplification. The 6/7-containing TrkA-specific primer set: forward primer 5 '-TGA AGG TCC AGG TGC CCA

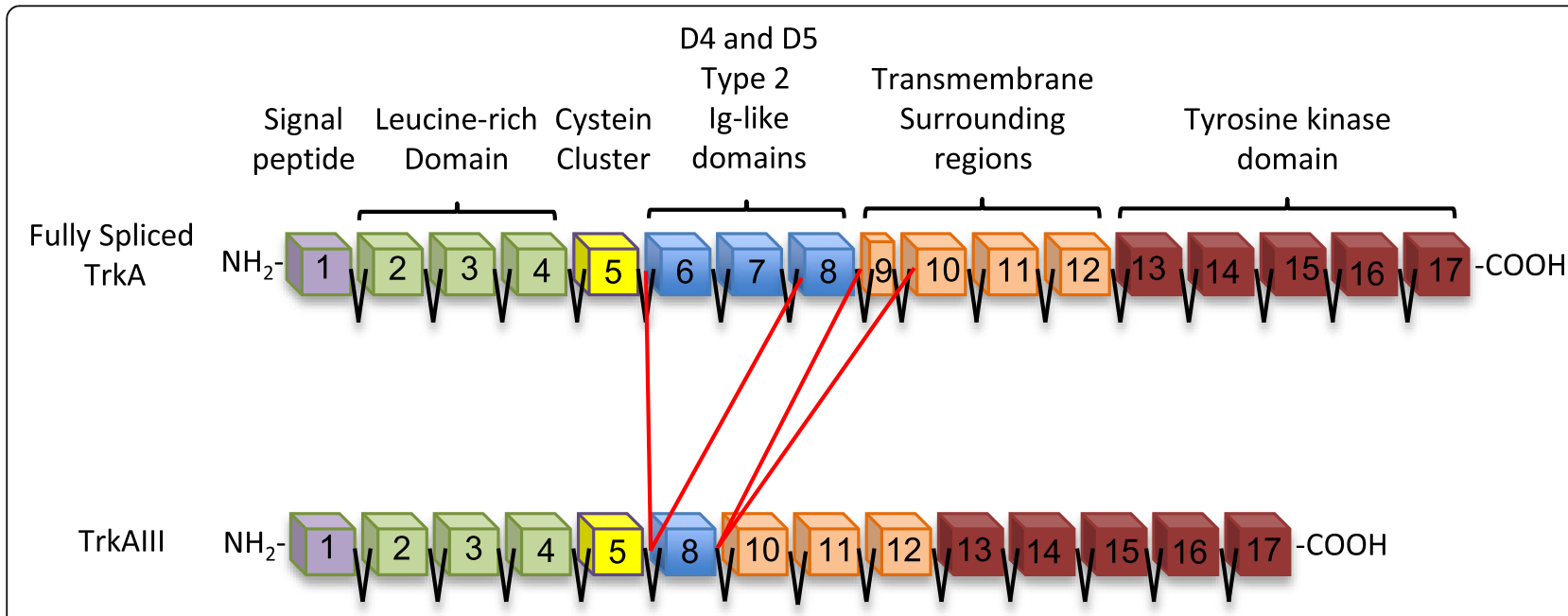

Exons 6, 7 and 9 skipping

Fig. 1 Fully spliced TrkA and alternatively spliced TrkAll exon structure. Schematic representation of the exon structures of fully spliced TrkA, with associated receptor domains, and alternatively spliced TrkAlll, exhibiting exons 6, 7 and 9 skipping and deletion of the D4 Ig-like domain 

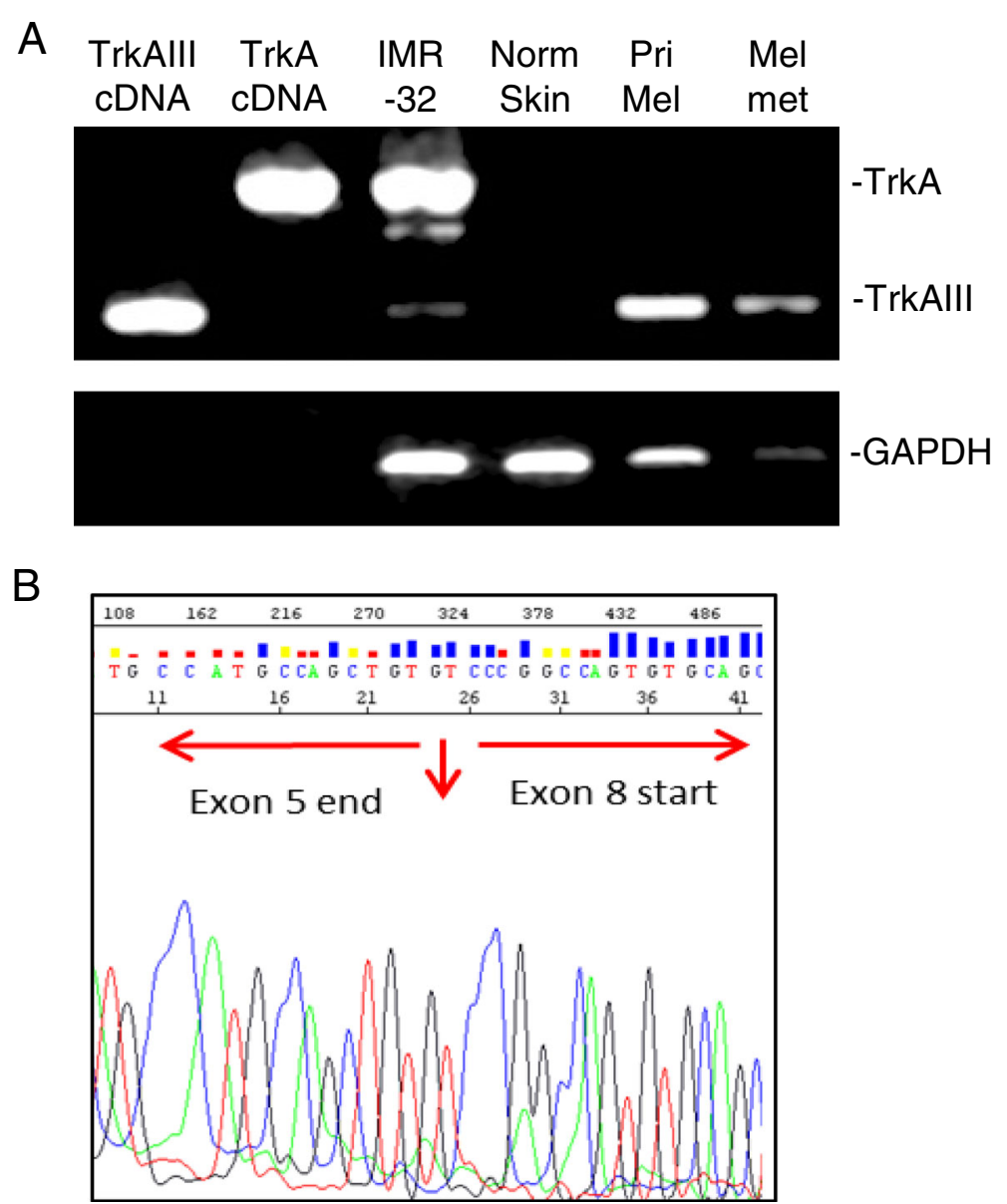

Fig. 2 TrkAlll is expressed in primary and secondary to metastatic melanomas. a) Representative RT-PCR agarose gel, demonstrating exclusive TrkAlll expression in a single primary melanoma (Pri Mel) and single melanoma metastasis (Mel Met) samples compared to predominant fully spliced TrkA expression in IMR32 NB cells and lack of TrkA expression in a sample of normal human skin plus TrkAlll and TrkA cDNA RT-PCR product controls and GAPDH, as a loading control. b) Representative TrkAlll exon 5/8 splice junction sequence from a melanoma metastasis

AT $-3^{\prime}$ and reverse primer 5' ${ }^{\prime}$-TTG ACC TGA ACA GAG ACC TCT GC-3', amplifies sequences contained within exons 6 and 7 but does not amplify TrkAIII cDNA.

True assessment of TrkAIII expression and function in human malignancies, however, suffers from a lack of TrkAIII-specific antibodies, making correlation between TrkAIII mRNA and protein expression difficult to assess in tumour samples. Furthermore, difficulty in obtaining TrkAIII expressing NB cells from TrkAIII expressing NB samples and the fact that alternative TrkAIII splicing is stress-regulated and likely, therefore, to be lost in vitro, as reported for the expression of EGFRvIII splice variant oncogene [28], has led to the predominant use of transfected cell lines to study TrkAIII oncogenic behaviour, raising some concerns. Development of a TrkAIII-specific antibody will, therefore, be critical for routine immunohistochemical detection of TrkAIII protein expression in order to identify tumours that express TrkAIII mRNA but not TrkAIII protein, which would not be expected to respond to Trk inhibitory therapy [18].

\section{Oncogenic alternative TrkAlll splicing: A De-regulated physiological stress-protection mechanism and tumour-promoting switch}

Stress-regulated alterative TrkAIII splicing is not only exhibited by neural and neural crest related tumour cells but also by normal human neural stem cells and neural crest-derived progenitors but not differentiated counterparts. TrkAIII is also expressed in normal embryonic and post-natal thymuses and by thymic epithelial cell and thymocyte subpopulations, suggesting that alternative TrkAIII splicing represents a developmentally-regulated physiological mechanism that is relatively restricted to neural-related stem/progenitor cells, the thymus and thymocytes, during development [19, 27, 29]. 
How this is subverted into an oncogenic mechanism in neural/neural crest-related cancers is not fully understood. A direct transforming role for TrkAIII would have to involve pre-existing changes in neuroblasts, such as functional pRB and/or p53 inactivation, implicated in single-oncogene transformation of NIH3T3 cells [30], induced by TrkAIII [19]. This could be enhanced by stress within the microenvironment, providing a way to transform tumour-suppressing TrkA signals into oncogenic signals from TrkAIII $[19,29]$. On the other hand, TrkAIII expression by normal non-altered neuroblasts would be expected to be temporary, reversible and insufficient to induce transformation. TrkAIII activation in neuroblasts, furthermore, would require overcoming intracellular spontaneous ligand-independent activation thresholds, which may differ in different intracellular compartments. TrkAIII spontaneous activation potential, already enhanced by deletion of the D4 spontaneous activation-prevention domain [19,31], could be increased by constant constitutive expression and/or by overexpression, resulting from $\operatorname{Trk} A$ gene amplification. In support of the latter, $\operatorname{Trk} A$ gene amplification has been detected in a wide a range of human cancers, including melanomas [13, 25], which express TrkAIII (Fig. 2) (manuscript in preparation). Spontaneous TrkAIII activation could also result from down-regulating the expression and activity of TrkA de-phosphorylating PTPases, such as Shp1 and PTP1B $[19,32]$, in a manner analogous to PTP1B regulation of the NB-associated oncogene Alk [33, 34], which may also influence potential interactions between Alk and TrkAIII [35].

Alternatively, neuroblasts transformed by oncogenes, such as Alk [33], may utilise stress-regulated alternative TrkAIII splicing to augment survival during tumour initiation and early expansion, with de-regulation into a fully-fledged oncogenic mechanism occurring at a later stage. In this scenario, alternative TrkAIII splicing could be reversed, increasing potential for spontaneous regression and post therapeutic event-free survival, both of which associate with NB expression of fully spliced TrkA [1, 2, 20, 36].

TrkAIII association with advanced stage metastatic disease, post-therapeutic relapse and worse prognosis [19-21], however, suggests that a significant proportion of NBs exhibit more permanent alternative TrkAIII splicing. This could result from $\operatorname{Trk} A$ splice site mutations that promote exon 6-7 skipping, although to date splice site mutations have not been detected in either TrkAIII expressing NBs [19] or melanomas (unpublished observations). Alternatively, we have also found that SV40 large T-Antigen promotes alternative TrkAIII splicing in SH-SY5Y NB cells transiently transfected with the plasmids expressing different combinations of SV40 large T and small t antigens (pw2dl: SV40 large T-ag alone, T +/t-; pw2t: small t-ag alone, $\mathrm{T}-/ \mathrm{t}+$; pw2: large $\mathrm{T}$-ag and small $\mathrm{t}$-ag, $\mathrm{T}+/ \mathrm{t}+$; and a negative control pw101: mutation-inactivated small $\mathrm{t}$-ag without $\mathrm{T}$-ag, $\mathrm{T}-/ \mathrm{t}-$ ) [37] (Fig. 3a). This novel, not previously published data suggests that polyoma virus infection, which has been associated with increased risk of $\mathrm{NB}$ and identified in $\mathrm{NB}$ samples (reviewed in [38]), may promote alternative TrkAIII splicing in neuroblasts. Furthermore, SV40 T-ag expression induces NB in mice [39]. Alternative TrkAIII splicing in NB cells is also promoted by cobalt salts [19], suggesting that heavy metals that induce oxidative stress may also de-regulate TrkA splicing. Finally, mechanisms that de-regulate splice factor expression and/or activity to induce alternative splicing, such as the DNA damage-, ER-stress and nutrient-stress responses [40-42], may also de-regulate alternative TrkAIII splicing. In support of this, novel not previously published observations indicate that treatment of SH-SY5Y NB cells with ER stress inducing agent dithiothreitol (DTT) or with with the non-metabolisable glucose-deprivation mimic 2-deoxy-glucose (2DG) promote alternative TrkAIII splicing (Fig. 3b and c).

\section{TrkAlll triggers a variety of pro-tumorigenic mechanisms}

TrkAIII induces malignant transformation of NIH 3 T3 cells [19] in a single oncogene transformation mechanism, characterising TrkAIII as the pathological equivalent of an engineered oncogenic TrkA D4 Ig-like domain deletion-mutant, previously described [31]. In transfected NB cells, TrkAIII but not fully spliced TrkA augments xenograft tumorigenicity in vitro and in vivo, comparable to TrkT3 oncogene, and also augments osteolytic bone metastasis and non-bone metastasis formation in a nude mouse xenograft metastasis model, confirming that TrkAIII promotes both primary tumorigenicity and metastatic capacity. TrkAIII promotion of osteolytic bone metastasis associates with osteoclast differentiation and expression of the osteoclastactivating cytokine RANKL [19, 23, 29]. The relatively hypoxic bone metastatic microenvironment, furthermore, provides a suitable environment to promote and maintain alternative TrkAIII splicing, suggesting that TrkAIII promotion of bone metastasis may represent a novel organ specific metastatic mechanism, supporting Paget's "Seed and Soil" hypothesis for organ specific metastasis [23].

\section{TrkAIII signaling}

In NB transfectants, NGF activation of fully spliced TrkA receptors results in receptor tyrosine phosphorylation and signaling through both PI3K/Akt/NF-kB and RAS/MAPK pathways, resulting in neuronal differentiation, characterised by inhibition of proliferation and 

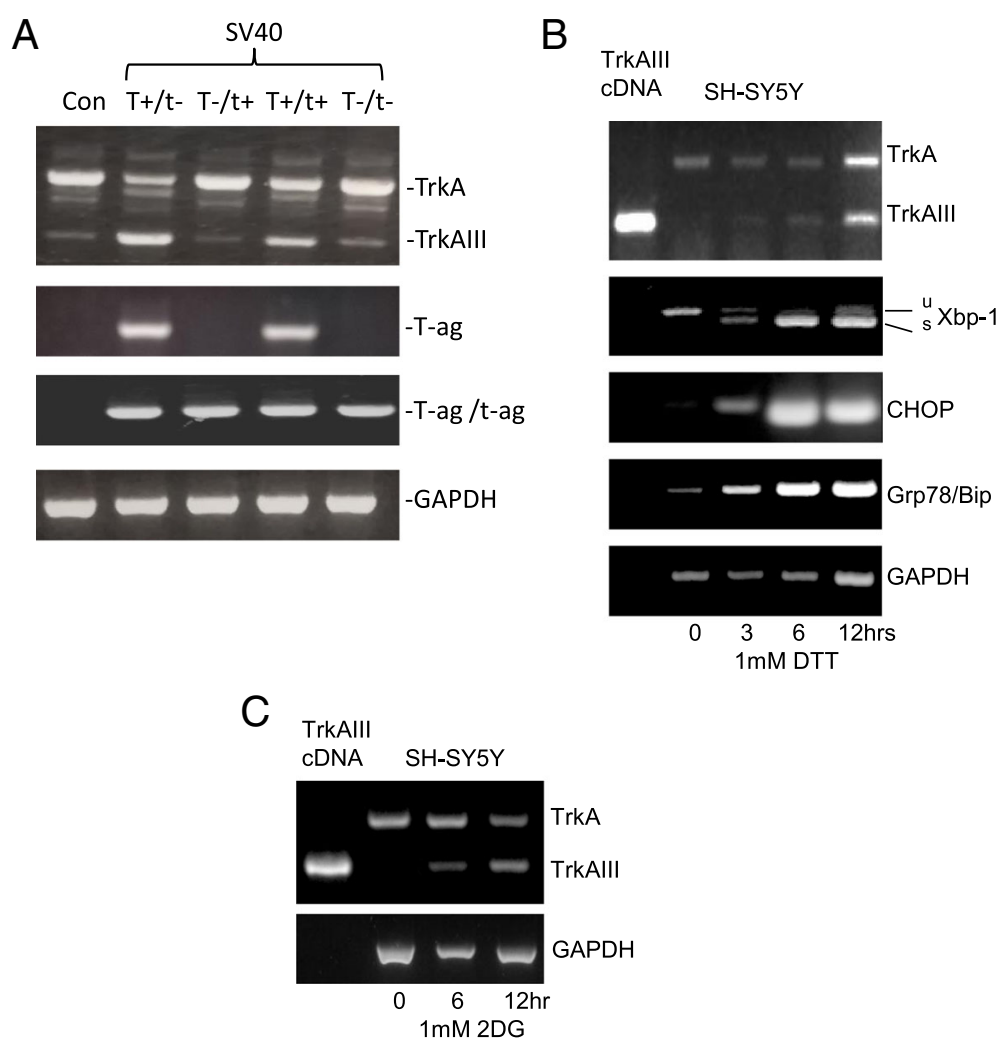

Fig. 3 SV40 large T antigen, DTT and 2-DG promote alternative TrkAlll splicing in NB cells. a) Representative RT-PCR agarose gel demonstrating the promotion of sequence verified alternative TrkAlll expression in SH-SY5Y NB cells, following transient transfection with plasmids pw2dl expressing SV40 large T-ag alone ( $\mathrm{T}+/ \mathrm{t}-$ ), pw2t expressing SV40 small tag alone ( $\mathrm{T}-/ \mathrm{t}+)$, pw2 expressing both large T-ag and small $\mathrm{t}$-ag $(\mathrm{T}+/ \mathrm{t}+)$ and negative control pw101 expressing only mutation inactivated small t-ag (T-/t-) compared to non-transfected control (Con). Large T-ag expression was confirmed by RT PCR amplification using T-ag specific primers whilst small tag expression was confirmed by deduction using a primer set that generates an identical fragment form both large T-ag and small tag CDNAs. b) Representative RT-PCR agarose gels demonstrating the promotion of alternative TrkAlll splicing in SH-SY5Y cells treated with 1 mM DTT for 3-12 h plus DTT-induced Xbp-1 splicing, CHOP and Grp78/Bip expression compared to GAPDH levels. c) Representative RT-PCR demonstrating induction of alternative TrkAlll splicing in SH-SY5Y cells treated for 6 and $12 \mathrm{~h}$ with the glucose deprivation mimic 2 deoxy-glucose (1 mM 2-DG) plus TrkAlll cDNA and GAPDH RT PCR controls

neuritogenesis $[1,19]$. In contrast, TrkAIII transfectants do not respond to extracellular NGF but exhibit spontaneous intracellular ligand-independent TrkAIII activation that results in chronic signaling through the PI3K/Akt/NF- $\mathrm{KB}$ but not RAS/MAPK pathway and continuous proliferation in the absence of neuritogenesis [19]. This implicates RAS/MAPK signaling in the NB tumour-suppressing effects of NGF-activated TrkA receptors and PI3K/Akt/NF- $k B$ without RAS/MAPK signaling in the diametrically opposed oncogenic activity of TrkAIII, which for some reason is unable to activate the RAS/MAPK pathway, despite binding Grb-2 and Frs-2 adapter proteins involved in RAS/MAPK activation [43].

\section{TrkAlll pro-Angiogenic PI3K/Akt/NF-KB signaling}

In contrast to fully spliced TrkA expression, which reduces NB xenograft tumorigenicity, tumour-associated angiogenesis and angiogenesis factor expression by $\mathrm{NB}$ cells [44, 45], xenograft tumours formed by TrkAIII transfectants are more vascular than tumours formed by control or fully spliced TrkA transfectants [19], consistent with a more angiogenic phenotype. In support of this, TrkAIII transfectants express elevated levels of the angiogenesis and metastasis-associated factors VEGF and MMP-9 and reduced levels of the angiogenesis inhibitors thrombospondin (Tsp)-1 and TIMP-3 compared to control and TrkA transfectants [19]. The MMP-9/ VEGF/Tsp1 equilibrium is considered critical for tumour angiogenesis, since MMP-9 activates VEGF and Tsp-1 inhibits both MMP-9 activation and VEGF activity $[46,47]$, and TIMP-3 is a potent angiogenesis inhibitor [48]. This pro-angiogenic equilibrium is regulated by PI3K in TrkAIII transfectants and is reversed by the PI3K inhibitor LY294002, which reduces VEGF and MMP9 expression and enhances Tsp-1 expression in TrkAIII transfectants [19]. 


\section{TrkAIII pro-survival PI3K/AKT/NF-KB signaling}

$\mathrm{PI} 3 \mathrm{~K} / \mathrm{Akt} / \mathrm{NF}-\mathrm{KB}$ signaling is also important for cell survival, and TrkAIII transfectants exhibit enhanced resistance to genotoxic- (cisplatin), oxidative- (paraquat, rotenone and LY83583) and ER-stress (DTT, A23187 and thapsigargin) [19, 32, 49]. Increased stress-resistance exhibited by TrkAIII transfectants associates with elevated expression and mitochondrial localisation of anti-apoptotic Bcl-2, Bcl-xL and Mcl-1 proteins and also with enhanced expression of the mitochondrial anti-oxidant SOD-2 [32, 49]. Trk tyrosine kinase inhibitors (K252a, CEP-701 and Gö6976), PI3K inhibitor (LY294002) and NF-kB inhibitors (dn-NF-kB and PDTC), all reduce Bcl-2, Bcl-xL and SOD2 expression in TrkAIII transfectants and increase sensitivity to genotoxic-, oxidative- and ER-stress induced death, confirming dependence upon TrkAIII tyrosine kinase, PI3K and NF-кB activity for survival [19, 32, 49].

Increased mitochondrial SOD2 expression and activity in TrkAIII transfectants attenuates constitutive and induced (paraquat, rotenone and LY83583) mitochondrial free-radical ROS production and increases resistance to agents that induce mitochondrial free radical-mediated death, identifying a novel TrkAIII/SOD2 mitochondrial protection axis [49].

\section{TrkAll mislocalization as a mechanism for oncogenic activity}

TrkAIII intracellular re-localisation and oncogenic behaviour supports the growing concept that mislocalization of TrkA-derived oncogenes underpins oncogenic signaling $[3,7,19,26,32,40,50]$. In contrast to fully-spliced cell surface TrkA receptors that associate with caveolin in low density membrane fractions [23] and exhibit tumour suppressing activity in NB [1, 19], TrkAIII receptors do not associate with caveolin in low density membrane fractions [23] and re-localise to intracellular pre-Golgi membranes, in which they exhibits spontaneous activation and self-perpetual recycling between the ER and ERGIC-COPI compartments [19, 40, 50]. Pulse chase and membrane purification analyses clearly demonstrate that TrkAIII exits the ER and arrives at the ERGIC [40, 50] but fails to exhibit anterograde transport to the Golgi Network (GN) [40]. Instead, TrkAIII exhibits spontaneous activation within ERGIC-COPI membranes, which results in microtubule (MT)-dependent, MT-minus end retrograde transport from the ERGIC/COPI compartment back to the ER, where TrkAIII is inactivated prior to returning once more to the ERGIC [39, 50]. This sets up self-perpetual ER and ERGIC-COPI recycling that not only ensures sufficient accumulation of TrkAIII within the ER to induce partial UPR activation but also sufficient accumulation of TrkAIII to overcome the spontaneous activation threshold within the ERGIC/COPI compartment and retrograde transport of TrkAIII back to the centrosome, where it complexes with both $\gamma$ - and $\alpha$-tubulin $[26,51]$. This behaviour is reminiscent of motor protein MT minus-end directed retrograde transport of activated cell surface TrkA receptors that translocate from axon terminals along axons to the neuronal cell body [52]. Furthermore, the inhibition of TrkAIII anterograde transport to the GN prevents GN-associated TrkAIII maturation. This can be overcome by Trk tyrosine kinase inhibitors (CEP-701, Gö6976 and GW441756), which promote anterograde TrkAIII transport to the GN, resulting in gp120kDa TrkAIII maturation and degradation at the proteasome [40]. Degradation of inactivated mature gp $120 \mathrm{kDa}$ TrkAIII at the proteasome, implicates the amino acid sequence deleted from TrkAIII in protecting fully spliced TrkA receptors from proteasome degradation as they translocate to the cell surface, as cell surface expression of mature gp $120 \mathrm{kDa}$ TrkAIII is only detected under TrkAIII and proteasome inhibitory conditions (Schematized in Fig. 4) [40, 53, 54].

Spontaneous TrkAIII activation within ERGIC/COPI membranes, confirmed by co-localisation with ERGIC and COPI markers in purified membrane fractions and also by confocal microscopy, is prevented by the COPI vesicle ARF-inhibitor Brefeldin A and indicates that the ERGIC/COPI membrane compartment is more permissive for TrkAIII activation [40]. This adds to reports that the COPII membrane compartment is permissive for Trk-oncogene activation and that immature TrkA receptors, blocked in anterograde transport, are aberrantly activated within ERGIC membranes $[55,56]$. It appears, therefore, that ERGIC/COP membranes exhibit a lower threshold for spontaneous TrkAIII activation than either ER or GN compartments [19, 31]. This lowered threshold is likely not only to depend upon changes in TrkAIII interactions within a vesicular context but also by lower levels of TrkAIII dephosphorylating PTPase within this membrane compartment. Activation within the ERGIC/ COPI compartment may also explain why TrkAIII does not activate the RAS/MAPK pathway, as the ERGIC/ COPI compartment would be dissociated from RAS/ MAPK components in the GN and cell surface compartments [57]. In support of this, immature TrkA receptors blocked in anterograde transport and activated within the ERGIC compartment do not activate RAS/MAPK signaling [56], supporting the role of RAS/MAPK signaling in the diametrically opposed tumour suppressing and oncogenic behaviours exhibited by TrkA and TrkAIII, respectively $[19,49,51]$.

TrkAIII, ER stress and the unfolded protein response (UPR) In addition to pro-survival and pro-angiogenic PI3K/ Akt/NF-кB signaling, TrkAIII expression also results in partial activation of a survival-adapted UPR, characterised by ATF6 but not Ire1a/Xbp-1 activation, and increased expression of the UPR chaperone Grp78/Bip 


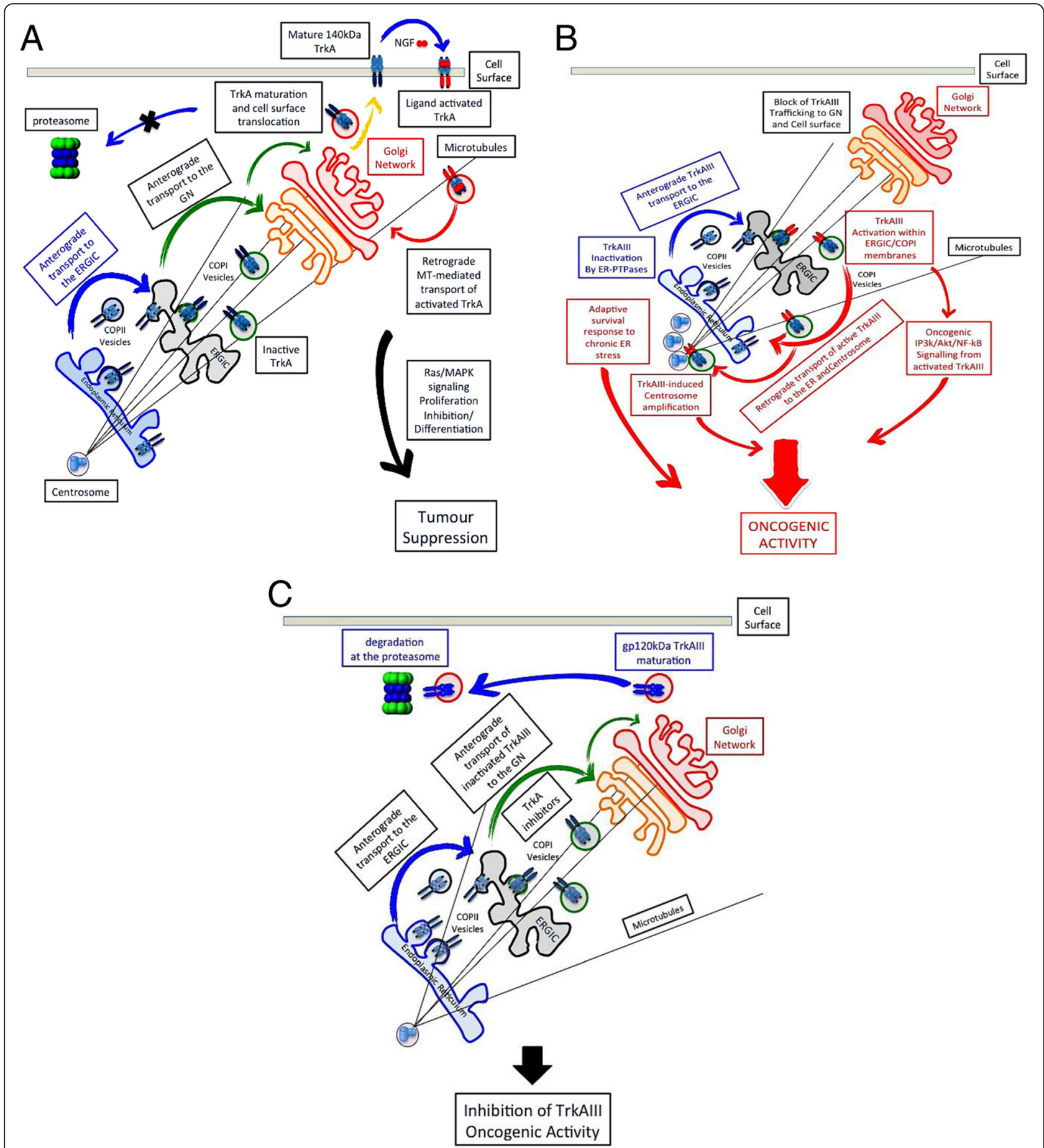

Fig. 4 TrkAlll recycles between the ERGIC and ER compartments. Schematic representation of: a) fully spliced TrkA receptor trafficking from intracellular to cell surface compartments, characterised by anterograde transport of inactive immature TrkA receptors from the ER to the ERGIC and GN, where they are matured prior to being transported to the cell surface plus the fate of neurotrophin-activated cell surface TrkA receptors that exhibit motor proteindependent MT minus-end directed retrograde transport to the GN, associated with the activation of tumour suppressing Ras/MAPK signaling. b) TrkAll intracellular trafficking, characterised by anterograde transport of inactive immature TrkAll from the ER to the ERGIC, spontaneous activation within ERGOC/ COPI membranes that blocks anterograde transport to the GN and promotes MT minus-end directed retrograde transport of active TrkAlll back to the ER and centrosome, setting up self perpetual TrkAlll recycling between the ER and ERGIC, partial UPR activation, PIP3K/Akt/NF-KB pro-survival and proangiogenic signaling, centrosome amplification, chromosome instability, formation of micronuclei and increased MTOC activity. c) Altered TrkAll trafficking in the presence of Trk tyrosine kinase inhibitor, characterised by the uninhibited anterograde transport of inactive TrkAlll from the ER to ERGIC and GN, resulting in GN-associated gp120kDa TrkAll maturation, degradation of mature TrkAlll at the proteasome and the inhibition of TrkAlll oncogenic activity 


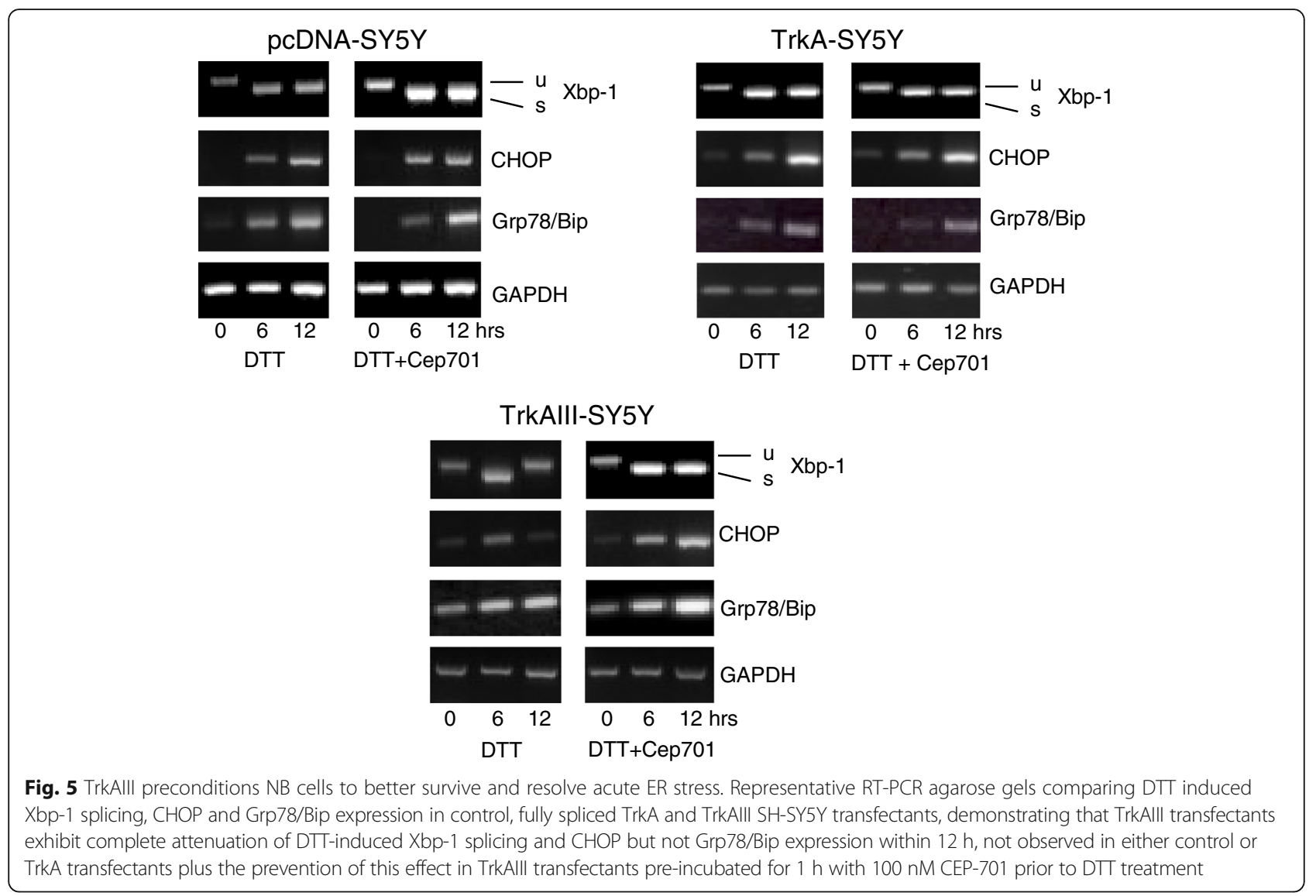

and the apoptosis inhibitor Mcl-1 [32, 40, 50, 58]. In TrkAIII transfectants, ER-associated TrkAIII is complexed with Grp78/Bip, confirming that TrkAIII has difficulty in satisfying ER quality control and helping to explain partial UPR activation [50]. The lack of constitutive Ire1a/Xbp-1 activation does not depend upon a defect in Ire1a/Xbp-1, as agents that induce acute ER stress readily activate Ire1a/Xbp-1 in TrkAIII transfectants (Figs. 3 and 5) [50]. Furthermore, Trk tyrosine kinase inhibitors do not induce Xbp-1 splicing in TrkAIII transfectants, indicating that lack of Ire1a/ Xbp-1 activation does not depend directly upon TrkAIII tyrosine kinase activity. This response, therefore, appears to represent a survival UPR adaptation to chronic sub-lethal ER stress, adding a novel "non-addiction" mechanism to TrkAIII oncogenic activity. This partial UPR, pre-conditions TrkAIII transfectants to better survive and resolve acute ER-stress, enhancing resistance to agents that induce ER stress compared to control and TrkA transfectants [32]. Furthermore, novel not previously published observations have detected a difference in the UPR induced by dithiothreitol (DTT) in control and TrkA transfectants, characterised by induction of Xbp-1 splicing and expression of the apoptosis promoter
CHOP that is maintained throughout the 12-h time course, when compared to TrkAIII transfectants in which DTT-induced Xbp-1 splicing and CHOP expression are rapidly attenuated, returning to normal levels by $12 \mathrm{~h}$ (Fig. 5), in association with enhanced survival [32]. The Trk inhibitor CEP-701 (100 nM) prolongs the UPR in TrkAIII transfectants (Fig. 5), in association with increased death [32]. Since, CHOP expression is regulated by PERK/ATF-4 and not by Ire1a/Xbp-1 [59-61], the attenuation of DTT-induced Xbp-1 splicing and CHOP expression in TrkAIII transfectants must reflect the inhibition of both PERK/ATF-4 and Ire1a activity, indicating a more rapid resolution of ER stress. This supports a role for constitutive TrkAIII tyrosine kinase activity combined with pre-existing TrkAIII-dependent ATF6 activation [50] and elevated Grp78/Bip, Bcl-2 protein and SOD2 expression [32, 58], in cellular pre-conditioning to better survive and resolve episodes of acute ER stress.

TrkAIIl, centrosome amplification, chromosomal instability and MTOC activity

Retrograde MT minus-end transport not only results in TrkAIII transport back to the ER but also translocation of activated TrkAIII to the centrosome, where it localises 
in complexes with $\gamma$ - and $\alpha$-tubulin $[26,51]$. TrkAIII, at the centrosome, tyrosine phosphorylates centrosome components, including Plk4, leading to de-regulation of centrosome duplication, resulting in centrosome amplification, increased multi-polar mitotic spindle formation, polyploidy, aneuploidy and the formation of micronuclei $[26,51]$. Micronuclei formation has been reported to drive metastasis through the cytosolic cGAS-STING DNA response [62], suggesting that TrkAIII activity at the centrosome resulting in micronuclei formation may represent an important metastasis driver mechanism, in addition to chromosomal instability. TrkAIII at the centrosome also tyrosine phosphorylates $\alpha$-tubulin and promotes MT polymerisation, augmenting MTOC activity during interphase. This results in the formation of short concentrated MT-arrays during interphase that promote nuclear anaplasia and help maintain NB cells in an undifferentiated state [51].

Therefore, retrograde TrkAIII transport and recycling between the ER and ERGIC/COPI compartments in addition to reinforcing ERGIC/COPI-associated TrkAIII activation, pro-survival and pro-angiogenic PI3K/Akt/ NF-кB signaling and a UPR survival-adaption also results in accumulation at the centrosome, promoting centrosome amplification, chromosome instability, micronuclei formation and MTOC activity, increasing metastatic potential and hindering differentiation.

\section{TrkAlll and sister chromatid exchange}

In addition to increasing chromosomal instability, TrkAIII transfectants also exhibit increased levels of sister chromatid exchanges, suggesting that TrkAIII may also promote replication-stress either by elevating levels of homologous recombination and/or the burden of single strand DNA breaks [26]. As for other oncogenes, this could be achieved by altering the expression of genes involved in licensing replication origins and/or replication fork elongation, de-regulating DNA replication dynamics and promoting genomic instability to drive tumorigenesis [63]. Furthermore, TrkAIII is also detected in nuclear extracts [23], suggesting that TrkAIII may also play a role within the nucleus.

\section{TrkAlll, differentiation and tumour cell staminality}

TrkA expression is a prerequisite for NB cell differentiation and NB regression, via RAS/MAPK-dependent inhibition of proliferation and induction of neuritogenesis $[1,19,36]$. TrkAIII transfectants do not respond to exogenous NGF and spontaneous intracellular TrkAIII activation does not activate RAS/MAPK signaling, resulting in continuous proliferation in the absence of neuritogenesis [19]. Furthermore, TrkAIII expression also inhibits the differentiation-inducing effects of NGF-activated TrkA signaling by preventing RAS/
MAPK activation, characterising TrkAIII as a potential pivotal regulator of NB cell differentiation in the presence of neurotrophins [19, 23]. TrkAIII transfectants also exhibit elevated expression of the NB tumour stem cell-markers CD117, SOX2, Nestin and Nanog, indicating that TrkAIII not only blocks NGF/TrkA-induced NB cell differentiation but also promotes a more NB tumour stem cell-like phenotype. This provides an additional explanation for the reported association between TrkAIII expression and advanced stage metastatic disease, post-therapeutic relapse and worse prognosis in NB, all of which associate with a more stem cell like phenotype [19-21].

\section{TrkAIII mitochondrial translocation and induction of the "Warburg" effect}

Continuous TrkAIII recycling between ER and ERGIC membranes [40] also leads to the re-localisation of TrkAIII to specialised membranes sites (MAMs) that link the ER to the mitochondria, resulting in TrkAIII association with outer mitochondrial membranes (OMM) [32]. Under normal conditions, OMM-associated TrkAIII is not constitutively tyrosine phosphorylated, indicating that the MAM-mitochondrial environment has a high threshold for spontaneous TrkAIII activation. However, under conditions of ER stress, induced by DTT, thapsigargin or A23187 calcium ionophore, OMM-associated TrkAIII is rapidly internalised into inner mitochondrial membranes (IMMs), where it is subjected to Omi/HtrA2-dependent cleavage-activation to $45-48 \mathrm{kDa} C \mathrm{C}$ active fragments, in mitochondrial matrix orientation [32]. Since TrkAIII does not posses a typical mitochondrial translocation sequence, mitochondrial importation under conditions of ER stress may be the result of the stress-regulated mitochondrial import mechanism for the uptake and degradation of damaged proteins that forms part of the mitochondrial UPR [64]. Activation of IMM-associated TrkAIII under conditions of ER stress is facilitated by $\mathrm{ROS} / \mathrm{Ca}^{2+}$ interplay, providing conditions necessary for activation of mitochondrial Omi/HtrA2, which is responsible for eliminating the remaining $\mathrm{N}$-terminal spontaneous activation-preventing sequences from TrkAIII, which together with ROS inactivation of mitochondrial PTPases facilitates the spontaneous activation of IMM-associated cleaved TrkAIII. The activation of IMM-associated TrkAIII results in the tyrosine phosphorylation of mitochondrial proteins including pyruvate dehydrogenase kinase-1, an inhibitor of the pyruvate dehydrogenase complex, resulting in a metabolic switch to aerobic glycolysis [32]. This identifies TrkAIII as a novel communicator of ER-stress to the mitochondria that results in metabolic adaptation, providing a mechanism through which ER-stress helps to maintain the metastasis-promoting "Warburg" metabolic effect in TrkAIII expressing tumour cells [64-67] (Schematized in Fig. 6). 


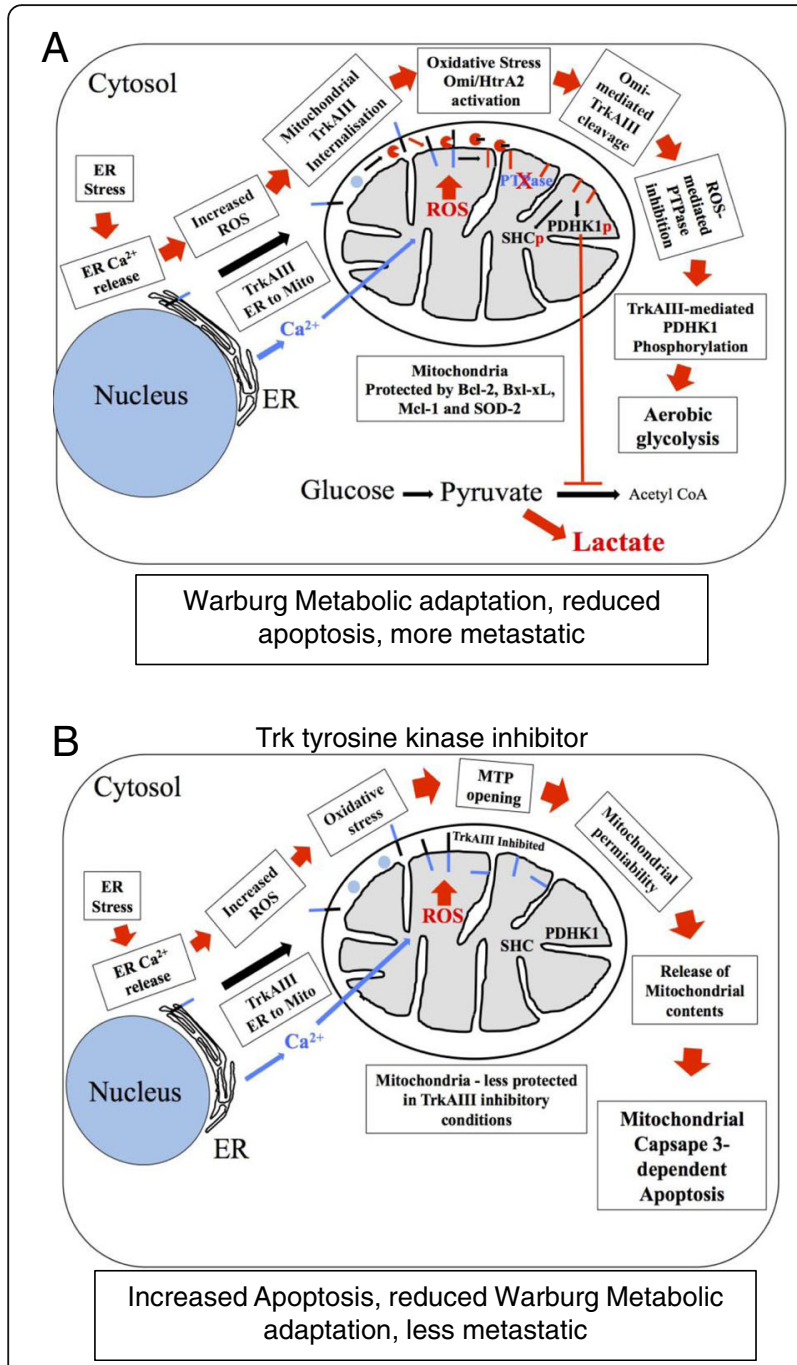

Fig. 6 ER-stress promotes mitochondrial TrkAll translocation, activation and the Warburg effect. Schematic representation of: a) ER stress induced translocation of MAM-associated TrkAlll into mitochondrial inner membranes, resulting in Omi/HtrA2-dependent TrkAlll cleavage activation, PDHK1 tyrosine phosphorylation and aerobic glycolytic

"Warburg" metabolic adaptation, involving ER Ca2+ release and uptake by mitochondria and increased ROS production, within the context of mitochondria protected against apoptosis by increased $\mathrm{BCl}-2$ proteins and SOD2 expression, and $\mathbf{b}$ ) The effect of Trk tyrosine kinase inhibitor on ER stress-induced mitochondrial TrkAlll translocation and cleavage but inactivation, leading to reduced Warburg metabolic adaptation and increased apoptosis, associated with reduced $\mathrm{BCl}-2$ protein and SOD2 expression

\section{TrkAlll and the hallmarks of cancer}

Cancer is characterised by 10 hallmarks, providing order to the many mechanisms involved in malignant transformation [68]. Our summary of the many ways TrkAIII influences the oncogenic process, clearly demonstrates the aberrant TrkAIII expression and activation regulate the majority, if not all of the hallmarks of cancer. Although TrkAIII influence on "Evasion of Growth
Suppression" and "Immortalization" hallmarks, have yet to be described, TrkAIII influences the hallmarks of "Immune Evasion" by up-regulating MMP-9, cFLIP and Mcl-1 expression [19, 32, 58]; "Tumour-associated Inflammation" through constitutive activation of the pro-inflammatory transcription factor NF-кB [19]; "Invasion and Metastasis" by up-regulating MMP-9 and down-regulating TIMP-3 expression [19]; "Angiogenesis" through PIP3K-mediated upregulation of MMP-9 and VEGF expression, down-regulation of TIMP-3 and thrombospondin-1 expression [19] and promotion of micronuclei formation [26]; "Genetic Instability" by increasing sister chromatid exchange and inducing centrosome amplification, resulting in aneuploidy [26]; "Apoptosis Resistance" by up-regulating Bcl2, Bcl-xL, Mcl-1 and SOD-2 expression and partial activation of a survival-adapted UPR [32, 58, 49]; "Metabolism" through ER stress-induced mitochondrial translocation, activation and PDHK1 tyrosine phosphorylation, resulting in a switch to aerobic glycolysis [40]; and "Sustained Proliferation" by activating chronic PI3K/Akt in the absence RAS/ MAPK signaling, inhibiting pro-differentiation signaling from NGF-activated TrkA and maintaining a tumour stem cell-like phenotype [19, 49] (Schematized in Fig. 7).

\section{Potential therapeutic approaches for TrkAlll-driven cancers}

Small molecule Trk tyrosine kinase inhibitors

Adult and childhood cancers driven by novel TrkA-fusion oncogenes exhibit profound and long-lived responses to the Trk inhibitor Larotrectinib [18]. This suggests that cancers driven by TrkAIII may also represent good candidates for small molecule therapeutic Trk tyrosine kinase inhibitors, such as Larotrectinib, Entrectinib, Cabozantinib, Merestinib, TRS-011, DS-6051b, MGCD516, PLX7486 and DCC-2710, currently employed in ongoing clinical trials for cancers driven by novel Trk-fusions or altered Trk activity $([11,12]$ and reviewed in [17]) or novel Trk inhibitors in development, for which patents have been issued [69]. The therapeutic efficacy of small molecule Trk inhibitors could also be enhanced if combined with cancer drugs that induce genotoxic-, oxidative- or ER-stress, which would be expected to augment tumour cell killing, upon inhibition of TrkAIII-dependent survival signaling.

\section{Inhibitors of TrkAIII expression}

TrkAIII expression can be directly inhibited by the TrkAIII-specific PNA inhibitor (KKAA) ${ }_{4}$-GGCCGGGAC ACA, or equivalent TrkAIII-specific inhibitory siRNAs, which decrease TrkAIII expression in TrkAIII transfectants and enhance sensitivity to cancer drugs $[26,50]$. As stated above, efficacy of TrkAIII expression inhibitors could be enhanced if combined with cancer drugs that induce genotoxic-, oxidative- or ER-stress, 


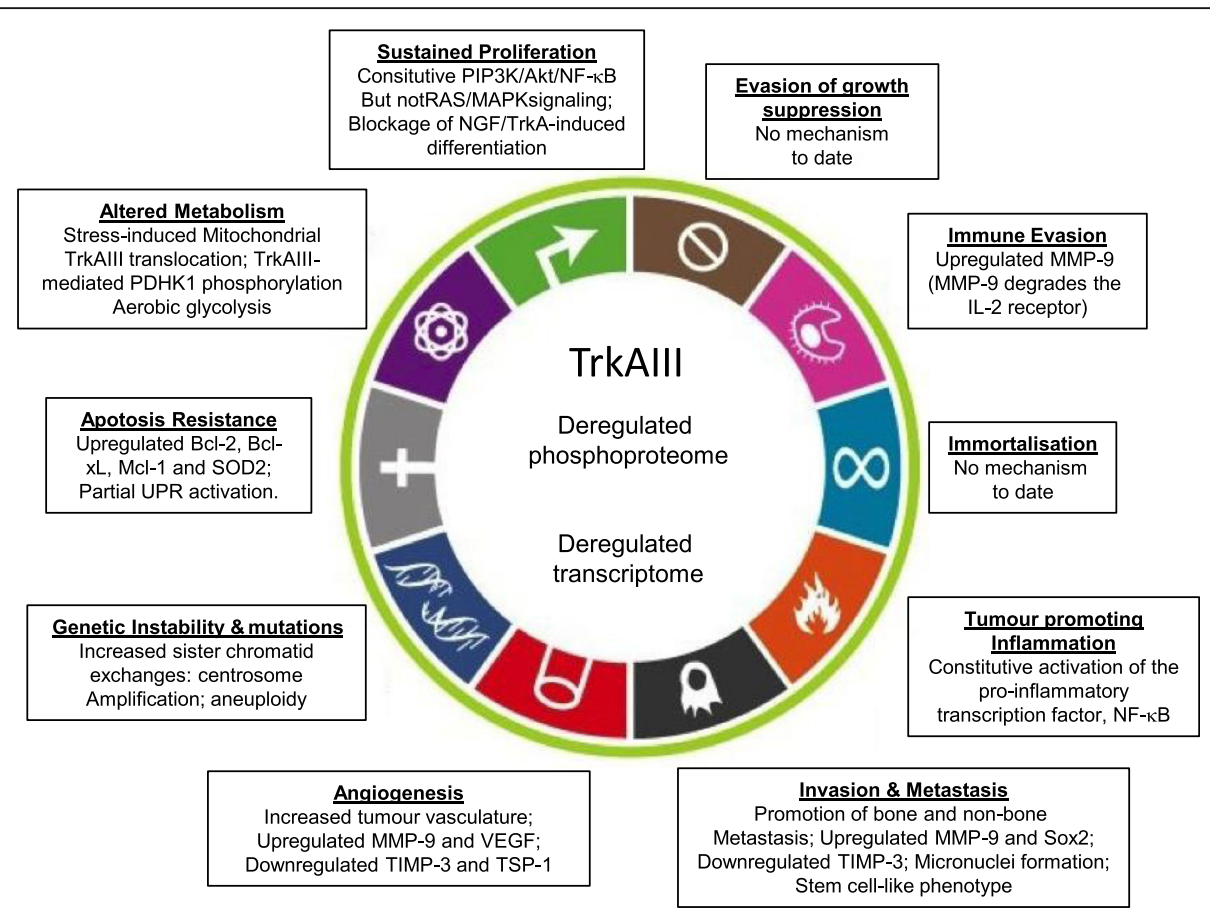

Fig. 7 TrkAlll influences the majority of Cancer Hallmarks. Schematic representation of TrkAlll deregulation of the phospho-proteome and transcriptome and how TrkAlll influences individual "Hallmarks of Cancer"

following a significant inhibition of TrkAIII expression and TrkAIII-dependent pro-survival signaling.

\section{Reversing alternative TrkAlll splicing}

Considering the NB tumour suppressing activity of fully spliced TrkA, reversal of alternative TrkAIII splicing back to fully spliced TrkA expression may represent an important therapeutic goal. This could be achieved using new generation lentiviral vectors engineered to express TrkAIII inhibitory siRNAs and the fully spliced TrkA coding sequence, mutated in wobble sites to prevent off-target inhibition by TrkAIII-specific siRNA, without altering the TrkA amino acid sequence. This approach would block TrkAIII oncogenic activity and reinstate TrkA tumour-suppressing activity, with potential to slow advanced disease progression, enhance chemotherapeuticsensitivity and increase the potential for spontaneous regression and post-therapeutic event-free survival, all of which associate with fully spliced TrkA expression $[1,20,36]$.

\section{Inhibition of PI3K/AKT/NF-KB signaling}

TrkAIII promotion of pro-survival and pro-angiogenic PI3K/Akt/NF-KB signaling exhibited by TrkAIII transfectants suggests that inhibitors of PI3K/Akt/NF-кB signaling could significantly slow tumour progressions, reduce tumour-associated angiogenesis and enhance chemotherapeutic-sensitivity. This could be achieved either by plant-derived PI3K inhibitors (reviewed in [70]), synthetic pan- and isoform-specific PI3K inhibitors and Akt inhibitors (reviewed in [71]) or by the $>700$ small molecule upstream NF-кB inhibitors of IKK activity, ІкB phosphorylation and ІкB degradation, inhibitors of NF- $\mathrm{KB}$ transactivation, proteasome activity and NF- $\mathrm{KB}$ inhibitory antioxidants (reviewed in [72]).

\section{Targeting the UPR}

TrkAIII induces partial activation of a survival-adapted UPR, which preconditions cells to better survive and resolve acute episodes of ER stress, in an important "nononcogene addiction" mechanism. Agents (siRNA, PNAs etc.) that reduce expression of the major UPR regulator Grp78/Bip, overexpressed by TrkAIII transfectants may target this mechanism to render TrkAIII-expressing tumour cells more sensitive to acute ER-stress-induced death. Down-regulation of Grp78/Bip expression could be achieved using the cancer drug OSU-03012, developed from Celecoxib, that supresses Grp78/Bip expression by $>90 \%$ in many tumour cell lines and significantly increases tumor cell killing [73]. Combining OSU-03012 with small molecule Trk inhibitors and agents that induce ER-stress may also slow disease progression by enhancing sensitivity to ER stress.

Targeting anti-apoptotic Bcl-2, Bcl-xl and Mcl1 proteins TrkAIII enhances NB cell resistance to genotoxic-, oxidative- and ER-stress by increasing the expression and mitochondrial-localisation of anti-apoptotic Bcl-2, 
Bcl-xL and Mcl-1 proteins [32, 58]. Therefore, agents that reduce $\mathrm{Bcl}-2, \mathrm{Bcl}-\mathrm{xL}$ and/or Mcl1 expression combined with small molecule Trk inhibitors and agents that promote mitochondrial apoptosis, would be expected to kill TrkAIII expressing tumour cells. Agents that down-regulate the expression of Bcl-2-family proteins, include: ABT-737, ABT-263 (Navitoclax) and ABT-199; WEHI-539; BXI-61 and BXI-72; Obatoclax; S1; JY-1-106; Apogossypol and derivatives [74], and agents that down-regulate Mcl-1 expression, include: Flavopiridol and SNS-032 cyclin-dependent kinase inhibitors; Sorafenib multi kinase inhibitor; WP1130 de-ubiquitinase inhibitor; antisense oligonucleotides; ABT-737 and Obatoclax BH3 mimetics, and Gossypol polyphenolic aldehyde and its derivative Sabutoclax (Bi-97C1) [75].

\section{Targeting the TrkAIII/SOD2 axis}

TrkAIII augments the expression of mitochondrial SOD-2, enhancing resistance to mitochondrial ROS-mediated death [49]. Down regulation of SOD2 expression would be expected to compromise this important mitochondrial protection mechanism and combined with small molecule Trk inhibitors and agents that promote mitochondrial ROS production, could increase TrkAIII-expressing tumour cell-sensitivity to mitochondrial ROS-mediated death and may also target the tumour stem cell-niche, which is promoted by TrkAIII and associated with enhanced SOD2 expression [49]. MiR-509-5p has been reported to down-regulates SOD2 expression and suppresses breast cancer metastatic progression [76]. MiR-509-5p mimics, therefore, could disrupt the TrkAIII/SOD2 mitochondrial protection axis to facilitate cancer drug-induced mitochondrial ROS-mediated death. However, the different roles played by SOD2 in cancer progression, metastasis and tumour inhibition [77], must be carefully assessed when considering SOD2 as a potential target.

\section{Maximising sensitivity to TRAIL-induced apoptosis}

The original pre-clinical promise of pro-apoptotic TRAIL/TRAIL-R signaling as a tumour-specific immunotherapy has been disappointing. Recombinant soluble TRAIL exhibits limit efficacy, short half-life and rapid clearance in vivo and first generation TRAIL-receptor agonists, designed to reduce toxicity, exhibit limited efficacy. Furthermore, many cancers including NB exhibit initial or acquired resistance to TRAIL-induced apoptosis and exogenous TRAIL may enhance the proliferation, invasive and metastatic behaviour of TRAIL-resistant tumour cells. These setbacks, however, have resulted in the development of innovative reagents and novel ways to increase half-life and overcome resistance, with major improvements in TRAIL

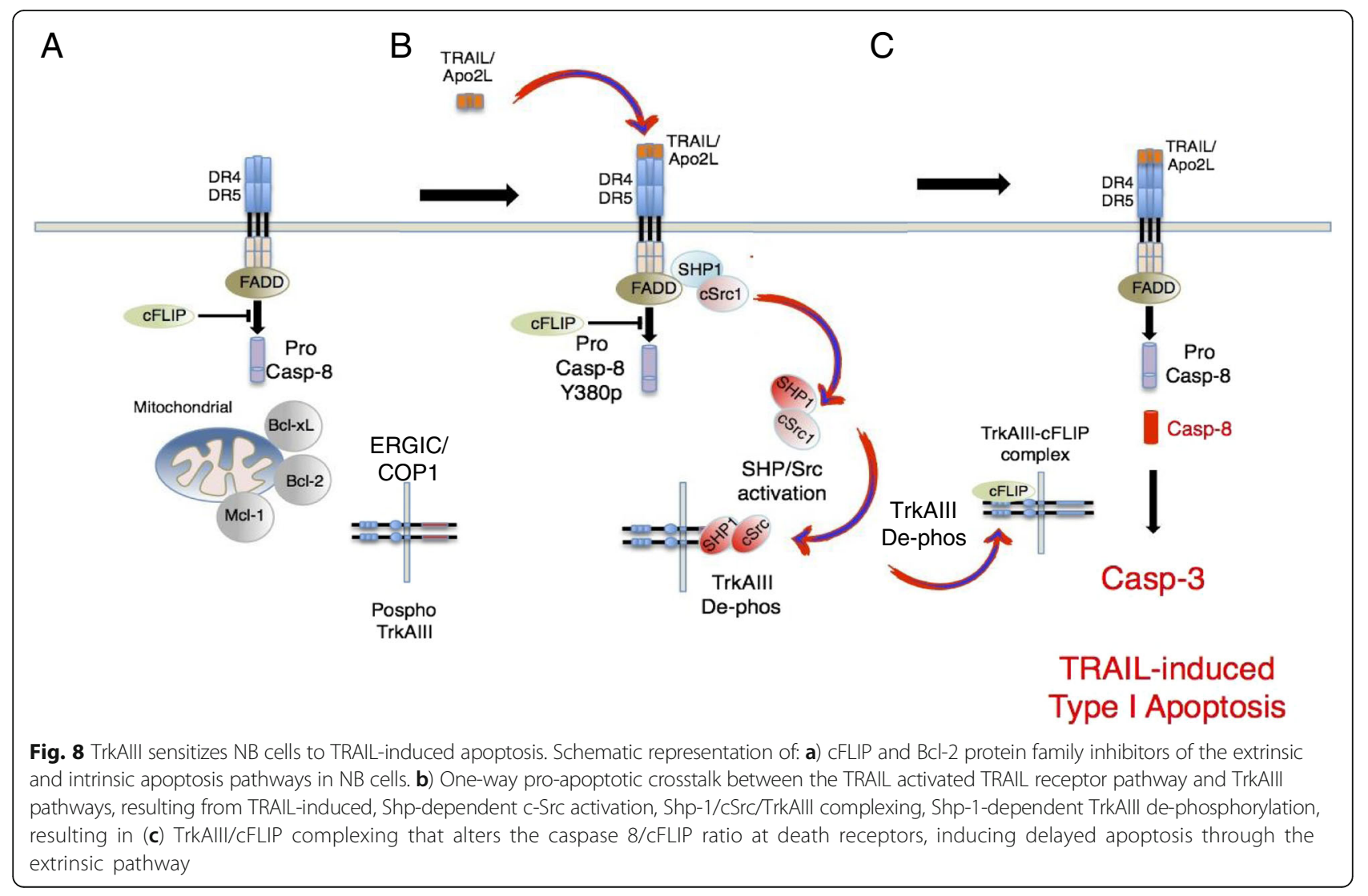


and TRAIL receptor-agonists, delivery and ways to overcome TRAIL-resistance (reviewed in [78-80]).

TrkAIII exhibits a potential therapeutic "Achilles heel" by sensitizing transfectants to one-way TRAIL-induced pro-apoptotic crosstalk between the TRAIL receptor signaling pathway and TrkAIII, resulting in delayed apoptosis and abrogation of tumorigenic activity in vitro [58]. In cells blocked in the intrinsic apoptosis pathway by elevated Bcl-2, Bcl-xL and Mcl1 expression [32, 58], TRAIL-induces delayed apoptosis through the extrinsic pathway [58]. This initiates with TRAIL-induced SHPmediated activation of $\mathrm{c}$-Src and the formation of complexes between activated TrkAIII, SHP-1 and c-Src. This results in SHP-mediated TrkAIII de-phosphorylation and the subsequent formation of complexes between de-phosphorylated TrkAIII and cFLIP. This alters the ratio of caspase- 8 to cFLIP at DR4/5 death receptors, in favour of caspase-8, resulting in delayed TRAIL-induced apoptosis. Furthermore, Mcl-1 and cFLIP play rate-limiting roles in TrkAIII transfectant-sensitivity to TRAIL-induced apoptosis, suggesting that cFLIP and/or Mcl-1 inhibitors, combined with novel TRAIL and
TRAIL-receptor agonist formulations could represent an important tumour-specific immunotherapy option for TrkAIII expressing tumours (Schematized in Fig. 8). TRAIL also induces apoptosis and abrogates the in vitro tumorigenic activity of NGF-activated TrkA expressing NB cells, via a mechanism that overcomes cFLIP-mediated resistance to TRAIL-induced apoptosis in the absence of NGF, adding a novel important pro-apoptotic immunological dimension to NGF/TrkA interactions in NB cells. This effect is temporary and is subsequently inhibited by NGF-dependent, NF-kB-mediated induction of $\mathrm{Mcl}-1$ expression, suggesting a potential pro-apoptotic use of painless NGF formulations and TRAIL combined with NF- $\mathrm{kB}$ and/or Mcl-1 inhibitors for favourable and unfavourable NBs that express fully spliced TrkA [81].

Therapeutic potential of geldanamycin A (GA)-analogues Hsp90 stabilises and promotes the activity of receptor tyrosine kinase (RTK) oncogenes, many of which are inhibited and/or induced to degrade by the Hsp90 inhibitor GA, prompting therapeutic evaluation and

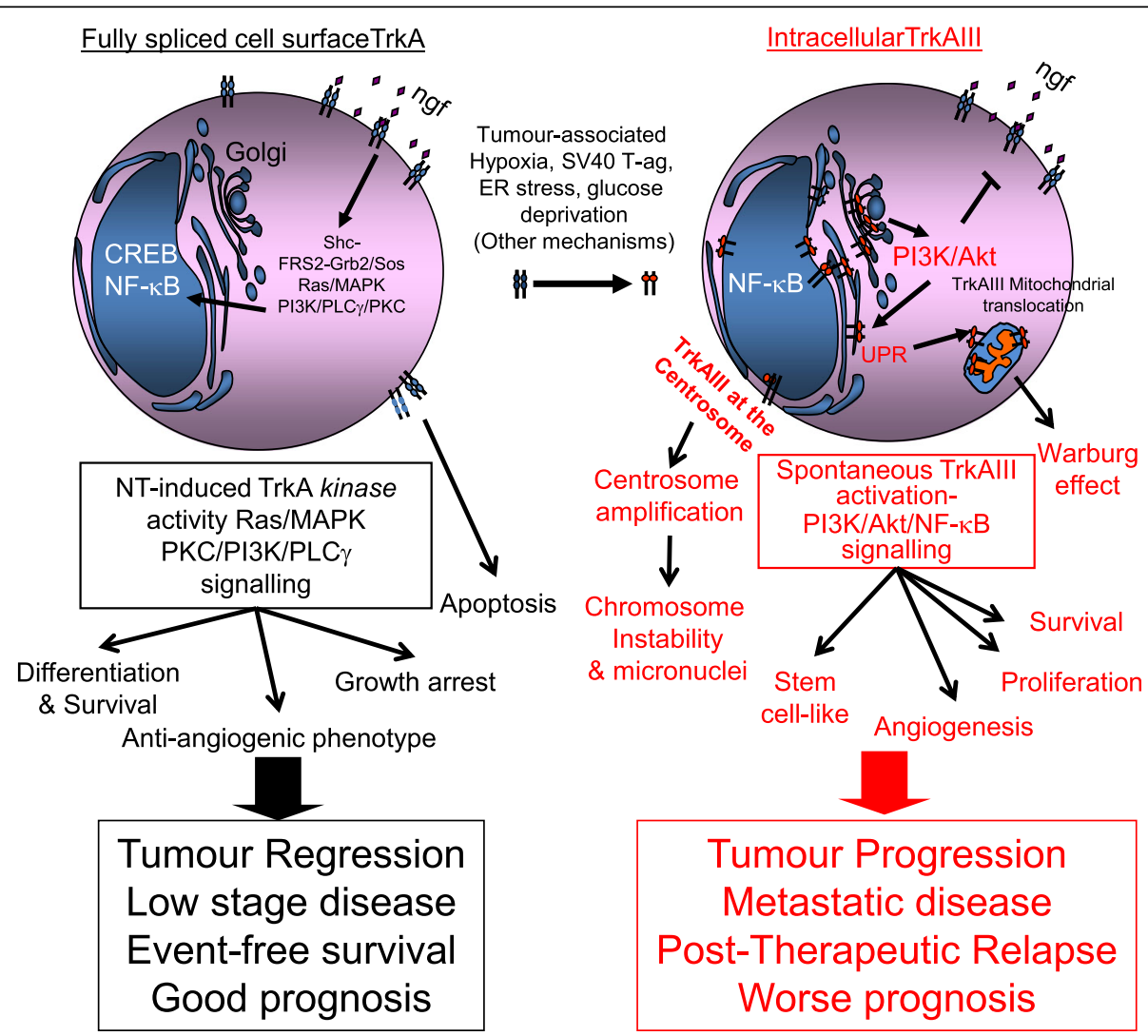

Fig. 9 Stress-regulated alternative TrkAlll splicing promotes neural- and neural-crest-related tumour progression. Schematic representation equating the tumour suppressing TrkA effects (differentiation, growth arrest, apoptosis and inhibition of angiogenesis) to the oncogenic TrkAlll effects (proliferation, staminality, stress resistance, survival, angiogenesis, genetic instability and the Warburg effect) resulting from D4 domain-deletion, receptor re- intracellular localisation, PIP3K/Akt/NF-KB, centrosome amplification and ER-stress induced translocation to and activation within the mitochondria 


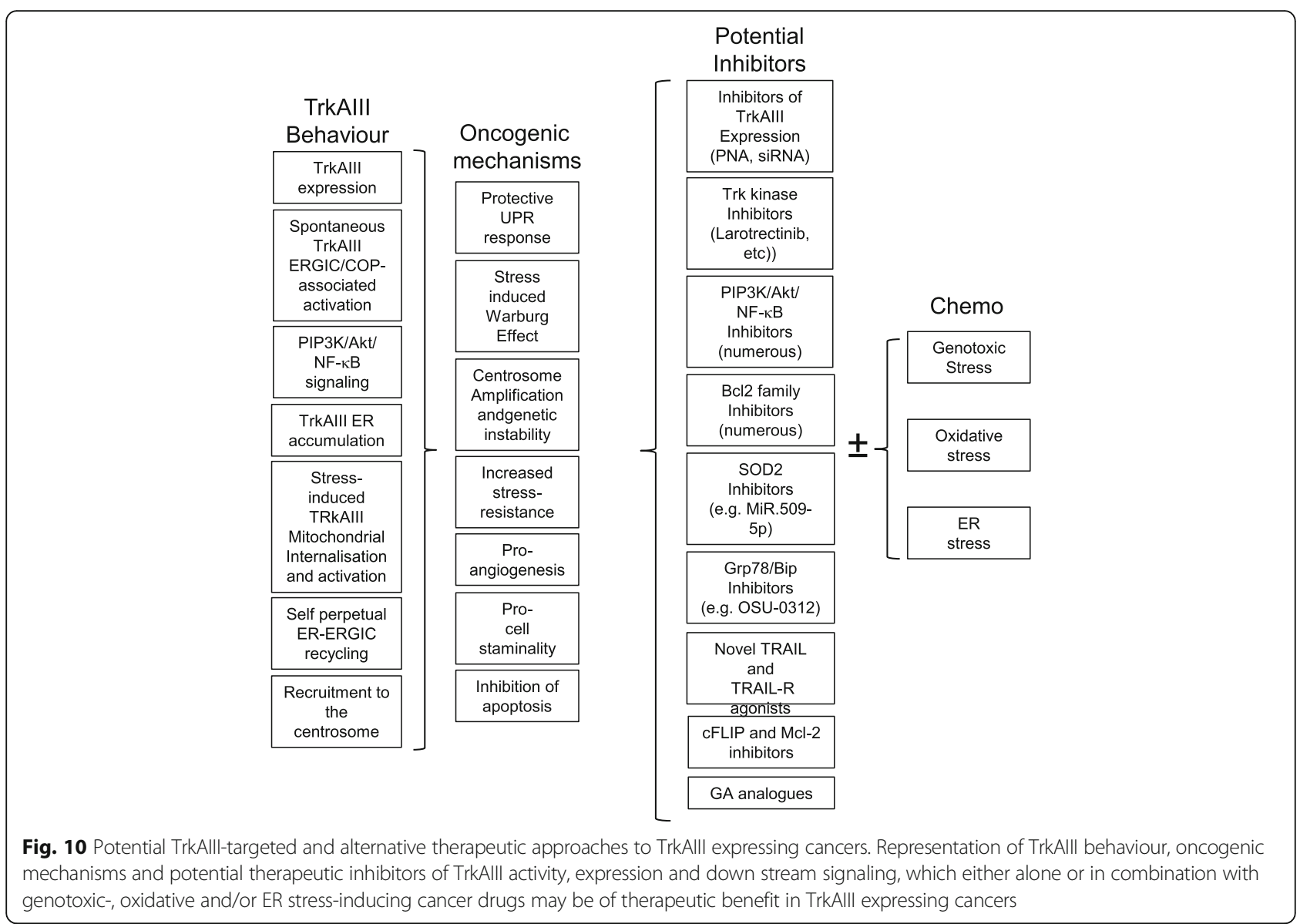

development of GA-analogues for use in adult and paediatric cancers, including NB [82]. TrkAIII also exhibits GA-sensitive interactions with Hsp90 and Grp94, critical for TrkAIII ER-export, spontaneous ERGIC/ COPI-associated activation and oncogenic function but not for TrkAIII stability [50]. In contrast to GA-analogue effects on tumours driven by other RTK oncogenes, however, TrkAIII exerts a negative impact upon GA-induced NB cell eradication, increasing TrkAIII ER-accumulation, resulting in rapid attenuation UPR-associated Ire1a/Xbp-1 activation and enhanced survival, when compared to control and TrkA transfectants. In TrkA/TrkAIII transfectant co-cultures, treatment with GA results in the selection of TrkAIII transfectants, which most likely depends upon preconditioning associated with constitutive partial UPR activation (see above), pre-existing PI3K/Akt/NF-KB survival signaling and elevated $\mathrm{Bcl}-2, \mathrm{Bcl}-\mathrm{xL}$ and Mcl-1 expression, which despite GA inhibition of TrkAIII activation, enhances survival. TrkAIII PNA inhibits this effect, indicating that the therapeutic potential of GA-analogues in TrkAIII expressing tumours would require combined inhibition of TrkAIII expression.

\section{Conclusions}

The profound, long-term therapeutic responses reported for TrkA fusion oncogene-driven cancers to Trk inhibitory therapy, highlights the need to better identify cancers driven by TrkA oncogenes, including TrkA oncogenes activated by aberrant alternative TrkA splicing, such as TrkAIII. The capacity of alternative splicing to unlock TrkA oncogenic potential, characterises sequence encoded within exons 6-7 in preventing oncogenic activation, the deletion of which causes receptor re-localization and spontaneous activation within altered intracellular substrate contexts, resulting in a plethora of "addiction" and "non-addiction" oncogenic mechanisms that impact upon a majority of the Hallmarks of Cancer (Schematized in Figs. 7 and 9). We propose, therefore, that efforts should be doubled to identify cancers potentially driven by aberrant alternative TrkAIII splicing in order to extend potential therapeutic options to include small molecule Trk tyrosine kinase inhibitors, inhibitors of PI3K/Akt/NF-кB signaling, inhibitors of $\mathrm{Bcl}-2$ protein family and/or SOD2 expression, reversal of alternative TrkAIII splicing or novel TRAIL or TRAIL-receptor agonist formulations. These approaches combined with existing genotoxic-, oxidative- and/or ER-stress inducing 
cancer drugs could result in important long-term therapeutic responses (Summarised in Fig. 10). Finally, alternative oncogenic TrkA splicing may not be limited to TrkAIII $[17,22]$, suggesting that characterisation of all oncogenic alternative TrkA splice variants may be required to fully exploit the therapeutic potential of Trk tyrosine kinase inhibitors and/or inhibitors of post receptor signaling.

\section{Abbreviations}

2DG: 2-deoxy-glucose; Alk: Anaplastic lymphoma kinase; ATF6: Activating transcription factor 6; BCl2: B cell lymphoma 2; BCl-xL: B cell lymphoma extra large; CFLIP: Cellular FLICE (FADD-like IL1 $\beta$-converting enzyme)-inhibitory protein; CHOP: C/EBP homologous protein; COP: Coatomer protein; DTT: Dithiothreitol; EGFR: Epithelial growth factor receptor; EGFRvIll: Epithelial growth factor receptor variant III; ER: Endoplasmic reticulum; ERGIC: Endoplasmic reticulum Golgi-intermediate compartment; GA: Geldanamycin A; GN: Golgi network; Grp78/BiP: Glucose related protein 78/binding immunoglobulin protein; Grp94: Glucose-related protein 94; HSP90: Heat shock protein 90; IMM: Inner mitochondrial membrane; Ire1a: Inositol requiring enzyme 1; IkB: Inhibitor kappa binding; MAM: Mitochondrial-associated ER membranes; MAPK: Mitogen activated protein kinase; Mcl-1: Myeloid leukemia cell differentiation protein; MiR: Micro RNA; MMP: Matrix metalloproteinase; MT: Microtubules; MTOC: Microtubule organising centre; NB: Neuroblastoma; NF-kB: Nuclear factor kappa-binding; NGF: Nerve growth factor; NT-3: Neurotrophin-3; Omi/HTRA2: High temperature requirement factor 2; OMM: Outer mitochondrial membrane; PDHK1: Pyruvate dehydrogenase kinase 1; PDTC: Ammonium pyrrolidinedithiocarbamate; PERK: Pancreatic endoplasmic reticulum kinase; PI3K: Phosphoinositol-3-kinase; PIk4: Polo kinase 4; PNA: Peptide nucleic acid; siRNA: Small inhibitory ribonucleic acid; SOD2: Superoxide dismutase 2; SV40: Simian virus 40; TIMP: Tissue inhibitor of metalloproteinases; TRAlL: Tumor necrosis factor-related apoptosis-inducing ligand; TRAIL-R: Tumor necrosis factor-related apoptosis-inducing ligand receptor; TrkA: Tropomyosin related kinase A; Tsp1: Thrombospondin 1; UPR: Unfolded protein response; VEGF: Vascular endothelial cell growth factor; Xbp1: Xbox binding protein 1

\section{Funding}

This article was funded by the Maugeri Foundation.

\section{Availability of data and materials}

Data supporting the conclusions of this article is included in this article and all other data concerning reviewed articles, for which data was obtained at the University of L'Aquila, are available from the authors upon reasonable request.

\section{Authors' contributions}

All authors made substantial contributions to articles reviewed in this manuscript, and were involved in the drafting and revision, and approved the final version of this manuscript.

\section{Ethics approval and consent to participate}

Manuscripts reviewed in this article, for which data was obtained at the University of L'Aquila, all received approval from the University of L'Aquila ethical committee.

\section{Consent for publication}

Not applicable.

\section{Competing interests}

The authors declare that they have no competing interests.

\section{Publisher's Note}

Springer Nature remains neutral with regard to jurisdictional claims in published maps and institutional affiliations.
Received: 16 May 2018 Accepted: 7 June 2018

Published online: 18 June 2018

\section{References}

1. Ruggeri P, Farina AR, Cappabianca L, lanni N, Ragone M, Merolla S, et al. Neurotrophin and neurotrophin receptor involvement in human neuroblastoma. In: Neuroblastoma, Prof Hiroyuki Shimada (Ed.). InTech, doi:https://doi.org/10. 5772/55536.

2. Aleo L, Rocco ML, Omar B, Micera A. Nerve growth factor: role in growth, differentiation and controlling cancer development. J Exp Clin Cancer Res. 2016;35:116. https://doi.org/10.1186/s13046-016-0395-y.

3. Martin-Zanca D, Hughes SH, Barbacid M. A human oncogene formed by the fusion of truncated tropomyosin and protein tyrosine kinase sequences. Nature. 1986;319:743-8.

4. Klein $\mathrm{R}$, Jing $\mathrm{S}$, Namduri V, O'Rourke $\mathrm{E}$, Barbacid $\mathrm{M}$. The trk proto-oncogene encodes a receptor for nerve growth factor. Cell. 1991;65:189-7.

5. Coulier F, Kumar R, Ernst M, Klein R, Martin-Zanca D, Barnacid M. Human Trk oncogenes activated by point mutation, in-frame deletion, and duplication of the tyrosine kinase domain. Mol Cell Biol. 1990;10:4202-10.

6. Greco A, Pierotti MA, Bongarzone I, Pagliardi S, Lanzi C, Della Porta G. Trk-T1 is a novel oncogene formed by the fusion of TPR and Trk genes in human papillary thyroid carcinomas. Oncogene. 1992;7:237-42.

7. Greco A, Mariani C, Miranda C, Lupas A, Pagliardini S, Pomati M, et al. The DNA rearrangement that generates the TrkT3 oncogene involves a novel gene on chromosome 3 whose product has a potential coiled-coil domain. Mol Cell Biol. 1995;15:6118-27.

8. George DJ, Suzuki H, Bova SG, Isaacs JT. Mutational analysis of the TrkA gene in prostate cancer. Prostate. 1998;36:172-80.

9. Reuther GW, Lambert QT, Caligiuri MA, Der CJ. Identification and characterisation of an activating TrkA deletion mutation in acute myeloid leukemia. Mol Cell Biol. 2000;20:8655-66.

10. Wiesner T, He J, Yelensky R, Esteve-Puig R, Botton T, Yeh I, et al. Kinase fusions are frequent in Spitz tumours and Spizoid melanomas. Nat Commun. 2014:5:3116. https://doi.org/10.1038/ncomms4116

11. Sartore-Bianchi A, Ardini E, Bosotti R, Amatu A, Valtorta E, Somaschini A, et al. Sensitivity to entrectinib associated with a novel LMNA-NTRK1 gene fusion in metastatic colorectal cancer. J Natl Cancer Inst. 2016;108 https:// doi.org/10.1093/jnci/djv306.

12. Wong V, Pavlick D, Brennan T, Yelensky R, Crawford J, Ross JS, et al. Evaluation of a congenital infantile fibrosarcoma by comprehensive genomic profiling reveals an LMNA-NTRK gene fusion responsive to crizotinib. J Natl Cancer Inst. 2016;108 https:/doi.org/10.1093/jnci/djv307.

13. Lockwood WW, Chari R, Coe BP, Girard L, MacAulay C, lam S, et al. DNA amplification is a ubiquitous mechanism of oncogene activation in lung and other cancers. Oncogene. 2008;27:4615-24.

14. Lee SJ, Kim NKD, Lee S-H, Kim ST, Park SH, Park JO, et al. NTRK gene amplification in patients with metastatic cancer. Prec Futur Med. 2017;1: 129-37.

15. Amatu A, Sartore-Bianchi A, Siena S. NTRK gene fusions as novel targets of cancer therapy across multiple tumour types. ESMO Open. 2016;1:e000023. https://doi.org/10.1136/esmopen-2015-000023.

16. Vaishnavi A, Le AT, Doeble RC. TRKing down an old oncogene in a new era of targeted therapy. Cancer Disc. 2015;5:25-34.

17. Lange AM, Lo H-W. Inhibiting TRK proteins in clinical Cancer therapy. Cancers. 2018;10 https://doi.org/10.3390/cancers10040105.

18. Drilon A, Laetsch TW, Kummer S, DuBois SG, Lassen UN, Demetri GD, et al. Efficacy of Larotrectinib in Trk-fusion-positive cancer in adults and children. N Engl J Med. 2018;378:731-9.

19. Tacconelli A, Farina AR, Cappabianca L, DeSantis G, Tessitore A, Vetuschi A, et al. TrkA alternative splicing: a regulated tumor-promoting switch in human neuroblastoma. Cancer Cell. 2004;6:347-60.

20. Schramm A, Schowe B, Fielitz K, Heilman M, Martin M, Marshall T, et al. Exon-level expression analysis identify MYCN and NTRK1 as major determinants of alternative exon usage and robustly predict neuroblastoma outcome. $\mathrm{Br} J$ Cancer. 2012;107:1409-17.

21. Simpson AM, lyer R, Mangino JL, Minturn JE, Zhao H, Kolla V, et al. TrkAlll isoform expression upregulates stem cell markers and correlates with worse outcome in neuroblastomas (NBs). Proc Adv Neuroblast Res. 2012;164:POT055.

22. Luberg K, Park R, Aleksejeva E, Timmusk T. Novel transcripts reveal a complex structure of the human TrkA gene and imply the presence of multiple protein isoforms. MBC Neurosci. 2015;16:78. doi.org/10.1186/s12868-015-0215-x 
23. Farina AR, Cappabianca L, Ruggeri P, Di lanni N, Ragone M, Merolla S, et al Alternative TrkA splicing and neuroblastoma. In: Neuroblastoma - Present and Future. London: Prof Hiroyuki Shimada (Ed) ISBN:978-953-307-016-2. InTech. 2012:111-136.

24. Florenes VA, Maelandsmo GM, Holm R, Reich R, Lazarovici P, Davidson B. Expression of activated TrkA protein in melanocytic tumors. Am J Clin Pathol. 2004;122:412-20.

25. Pasini L, Re A, Tebaldi T, Ricci G, Boi S, Adami $V$, et al. TrkA is amplified in malignant melanoma patients and induces an anti-proliferative response in cell lines. BMC Cancer. 2015;15:777. https://doi.org/10.1186/s12885-015-1791-y.

26. Farina AR, Tacconelli A, Cappabianca L, Cea G, Panella S, Chioda A, et al. The alternative TrkAlll splice variant targets the centrosome and promotes genetic instability. Mol Cell Biol. 2009;29:4812-30.

27. Tacconelli A, Farina AR, Cappabianca L, Cea G, Panella S, Chioda A, et al. TrkAlll expression in the thymus. J Neuroimmunol. 2007;183:151-61.

28. Gan HK, Cvrljevic AN, Johns TG. The epidermal growth factor receptor variant III (EGFRvIII): where wild things are altered. FEBS J. 2013;280:5350-70.

29. Tacconelli A, Farina AR, Cappabianca L, Gulino A, Mackay AR. Alternative TrkAlll splicing: a potential regulated tumor promoting switch in neuroblastoma. Future Oncol. 2005;1:689-98.

30. Kavsan VM, lershov AV, Balynska OV. Immortalized cells and one oncogene in malignant transformation: old insights on new explanation. BMC Cell Biol. 2011;12:23. https://doi.org/10.1186/1471-2121-12-23.

31. Arevalo JC, Conde B, Hempstead BL, Chao MV, Martin-Zanca D, Perez P. TrkA immunoglobulin-like ligand binding domains inhibit spontaneous activation of the receptor. Mol Cell Biol. 2000;20:5908-16.

32. Farina AR, Cappabianca L, Gneo L, Ruggeri P, Mackay AR. TrkAlll signals endoplasmic reticulum stress to the mitochondria in neuroblastoma cells, resulting in glycolytic metabolic adaptation. Oncotarget. 2018;9:8368-90.

33. Mossé YP, Laudenslager M, Longo L, Cole KA, Wood A, Laquaglia MJ, et al. Identification of ALK as a major familial neuroblastoma predisposition gene. Nature. 2008:455:930-5.

34. Boutterin MC, Mazot P, Faure C, Doly S, Gervasi N, Tremblay MI, et al. Control of ALK (wild type and mutated forms) phosphorylation: specific role for the phosphatase PTP1B. Cell Signal. 2013;25:1505-13.

35. Shi W, George SK, George B, Curry CV, Murzabdillaeva A, Alkan S, et al. TrkA is a binding partner of NPM-Alk that promotes survival of ALK+ T-cell lymphoma. Mol Oncol. 2017;11:1189-207.

36. Brodeur GM. Spontaneous regression of neuroblastoma. Cell Tissue Res. 2018:372:277-86.

37. Bochetta M, Di Resta I, Powers A, Fresco R, Tosolini A, Testa JR, et al. Human mesothelioma cells are unusually susceptible to simian virus 40-mediated transformation and asbestos carcinogenicity. Proc Natl Acad Sci U S A. 2000; 97:10214-9.

38. IARC Monographs on the evaluation of carcinogenic risks to humans Malaria and some polyoma viruses (SV40, BK, JC and Merkel cell viruses) (World Health Organisation international agency for research of Cancer, Geneva Switerland) 2014;104:133-251.

39. Iwakura H, Ariyasu H, Kanamoto N, Hosoda K, Nakao K, Kangawa K, et al. Establishment of a novel neuroblastoma mouse model. Int J Oncol. 2008;33: 1195-9.

40. Farina AR, Cappabianca L, Ruggeri P, Gneo L, Maccarone R, Mackay AR. Retrograde TrkAllI transport from ERGIC to ER: a re-localisation mechanism for oncogenic activity. Oncotarget. 2015;6:35636-51.

41. Chen J, Crutchley J, Zhang D, Owzar K, Kastan MB. Identification of a DNA damage-response alternative splicing pathway that regulates p53 and cellular senescence markers. Cancer Discov. 2017;7:766-81.

42. Li Z, Vuong JK, Zhang M, Stork C, Zheng S. Inhibition of nonsense-mediated RNA decay by ER stress. RNA. 2017;23:378-94.

43. Goto N. Regulation of growth factor signaling by FRS2 family docking/ scaffold adaptor proteins. Cancer Sci. 2008;99:1319-25.

44. Eggert A, Grotzer MA, Ikegaki N, Liu XG, Evans AE, Brodeur GM. Expression of neurotrophin receptor TrkA inhibits angiogenesis in neuroblastoma. Med Pediatr Oncol. 2000;35:569-72.

45. Eggert A, Grotzer MA, Ikegaki N, Liu XG, Evans AE, Brodeur GM. Expression of the neurotrophin receptor TrkA down-regulates expression and function of angiogenic stimulators in SH-SY5Y neuroblastoma cells. Cancer Res. 2002; 62:1802-8.

46. Bergers G, Brekken R, McMahon G, Vu TH, Itoh T, Tamaki K, et al. Matrix metalloproteinase- 9 triggers the angiogenic switch during carcinogenesis. Nat Cell Biol. 2000;2:737-44.
47. Rodriguez-Manzaneque JC, Lane TF, Ortega MA, Hynes RO, Lawler J, IruelaArispe ML. Thrombospondin-1 suppresses spontaneous tumor growth and inhibits activation of matrix metalloproteinase- 9 and mobilization of vascular endothelial cell growth factor. Proc Natl Acad Sci U S A. 2001;98: 12485-90.

48. Qi JH, Ebrahem Q, Moore N, Murphy G, Claesson-Welsh L, Bond M, et al. A novel function for tissue inhibitor of metalloproteinases-3 (TIMP-3): inhibition of angiogenesis by blockage of VEGF binding to VEGF receptor-2. Nature Med. 2003;9:407-15.

49. Ruggeri P, Farina AR, Di lanni N, Cappabianca L, Ragone M, lanni G, et al. The TrkAlll oncoprotein inhibits mitochondrial free radical ROS-induced death of SH-SY5Y neuroblastoma cells by augmenting SOD-2 expression and activity at the mitochondria, within the context of a tumor stem celllike phenotype. PLoS One. 2014;15:e94568.

50. Farina AR, Tacconelli A, Cappabianca L, Cea G, Chioda A, Romanelli A, et al. The neuroblastoma tumour suppressor TrkAl and its oncogenic alternative TrkAlll splice variant exhibit geldanamycin-sensitive interactions with Hsp90 in human neuroblastoma cells. Oncogene. 2009;28:4075-94.

51. Farina AR, Di lanni N, Cappabianca L, Ruggeri P, Ragone M, lanni G, et al. TrkAlll promotes microtubule nucleation and assembly at the centrosome in SH-SY5Y neuroblastoma cells, contributing to an undifferentiated anaplastic phenotype. Biomed Res Int. 2013;2013:740187. https://doi.org/10.1155/2013/ 740187.

52. Moughamian AJ, Osborn GE, Lazurus JE, Maday S, Holzbauer ELF. Predered recruitment of dynactin to the microtubule plus end is required for efficient initiation of retrograde axonal transport. J Neurosci. 2013;33:13190-203.

53. Watson FL, Porcionatto MA, Battacharyya A, Stiles CD, Segal RA. TrkA glycosylation regulates localisation and activity. J Neurobiol. 1999;39:323-36.

54. Farina AR, Cappabianca L, Ruggeri P, Gneo L, Mackay AR. The enemy from within: mislocalization of a compromised receptor as a mechanism for TrkAlll oncogenic activity. Cancer Cell Microenviron. 2016;3(1):1-5. https:// doi.org/10.14800/com.1205.

55. Johnson A, Bhattachary N, Hanna M, Pennington JG, Schuh A, Wang L, et al. TGF clusters COPII-coated transport carriers and promotes early secretory pathway organisation. EMBO J. 2015;7:811-27.

56. Schectersen LC, Hudson MP, Ko M, Philippidou P, Akmentin W, Wiley J, et al. Trk activation in the secretory pathway promotes Golgi fragmentation. Mol Cell Neurosci. 2010;43:403-13.

57. Prior IA, Hancock JF. Ras trafficking, localisation and compartmentalised signaling. Semin Cell Dev Biol. 2012;23:145-53.

58. Gneo L, Ruggeri P, Cappabianca L, Farina AR, Di lanni N, Mackay AR. TRAlL induces pro-apoptotic crosstalk between the TRAIL-receptor signaling pathway and TrkAlll in SH-SY5Y cells, unveiling a potential therapeutic "Achilles heel" for the TrkAlll oncoprotein in neuroblastoma. Oncotarget. 2016;7:80820-41.

59. Li Y, Guo Y, Tang J, Jiang J, Vhen Z. New insights into the roles of CHOPinduced apoptosis in ER stress. Acta Biochim Biophysi Sin. 2014;46:629-40.

60. Corazzari M, Gagliardi M, Fimia GM, Piacentini M. Endoplasmic reticulum stress, unfolded protein response and cancer cell fate. Frontiers in Oncol. 2017;7 https://doi.org/10.3389/fonc.2017.00078.

61. Hetz C, Lee A-W, Gonzalez-Romero D, Thielen P, Castilla J, Soto C, et al. Unfolded protein response transcription factor XBP-1 does not influence prion replication or pathogenesis. Proc Nat Acad Sci USA. 2008;105:757-62.

62. Bakhoum SF, Ngo B, Laughney AM, Cavallo J-A, Murphy CJ, Ly P, et al. Chromosomal instability drives metastasis through a cytosolic DNA response. Nature. 2018;533:467-72.

63. Sarni D, Kerem B. Oncogene-induced replication stress drives genome instability and tumorigenesis. Int J Mol Sci. 2017;18:1339. https://doi.org/10. 3390/ijms18071339.

64. Ruan L, Zhou C, Jin E, Kucharavy A, Zhang Y, Wen Z, et al. Cytosol proteostasis through importing of misfolded proteins into mitochondria. Nature. 2017;543: 443-6.

65. Libert MV, Locasale JW. The Warburg effect: how does it benefit cancer cells. Trends in Biochem Sci. 2016:41:211-8.

66. Lee N, Kim D. Cancer metabolism: Fuelling more than just growth. Mol Cells. 2016;39:847-54.

67. Menendez JA, Joven J, Cufi S, Corominas-Faja B, Oliveras-Ferraros C, Cuyas E, et al. The Warburg effect version 2.0: metabolic reprogramming of cancer stem cells. Cell Cycle. 2013;12:1166-79.

68. Hanahan D, Weinberg RA. Hallmarks of cancer: the next generation. Cell. 2011;144:646-74. 
69. Bailey JJ, Schirrmacher R, Farrell K, Bernard-Gauthier V. Tropomyosin receptor kinase inhibitors: an updated patent review for 2010-2016 - part II. Exp Op Ther Pat. 2017; https://doi.org/10.1080/13543776.2017.1297797.

70. Suvarna V, Murahari M, Khan T, Chaubey P, Sangave P. Phytochemicals and PI3K inhibitors in Cancer - an insight. Front Pharmacol. 2017;8 https://doi. org/10.3389/fpharm.2017.00916.

71. Janku F, Yap TA, Meric-Bernstam F. Targeting PI3K pathway in cancer: are we making headway? Nat Rev Clin Oncol. 2018;15:273-91.

72. Gupta SC, Sundaram C, Reuter S, Aggarwal BB. Inhibiting NF-kB activation by small molecules as a therapeutic strategy. Biochim Biophys Acta. 2010; 1799:775-87.

73. Booth L, Cazanave SC, Hamed HA, Yacoub A, Ogretmen B, Chen C-S, et al. OSU-30102 suppresses GRP78/BiP expression that causes PERK-dependent increase in tumor cell killing. Cancer Biol Ther. 2012;13:2234-6.

74. Vogler M. Targeting BCL2-proteins for the treatment of solid tumours. Adv Med. 2014;2014 https://doi.org/10.1155/2014/943648.

75. Quinn BA, Dash R, Azab B, Sarkar S, Das SK, Kumar S, et al. Targeting Mcl-1 for the therapy of cancer. Exp Op Invest Drugs. 2011;20:1397-411.

76. Song Y-H, Wang J, Nie G, Chen Y-J, Li X, Jiang X, et al. MicroRNA-509-5p functions as an anti-oncogene in breast cancer via targeting SOD2. Eur Rev Med Pharmacol Sci. 2017;21:3617-25.

77. Hempel N, Carrico PM, Melendez JA. Manganese superoxide dismutase (Sod2) redox-control of signaling events that drive metastasis. Anti Cancer Agents Med Chem. 2011;11:191-201.

78. Von Karsdtedt S, Montinaro A, Walczak H. Exploring the TRAlLs less travelled: TRAIL in cancer biology and therapy. Nat Rev Cancer. 2017;17:352-66.

79. Wu X, Wang S, Li M, Wang A, Zhou Y, Li P, et al. Nanocarriers for TRAlL delivery: driving TRAlL back on track for cancer therapy. Nano. 2017;9: 13879-904.

80. Dubuisson A, Micheau O. Antibodies and derivatives targeting DR4 and DR5 for cancer therapy. Antibodies. 2017;6:16. https://doi.org/10.3390/antib40016.

81. Ruggeri P, Cappabianca L, Farina AR, Gneo L, Mackay AR. NGF sensitizes TrkA SH-SY5Y neuroblastoma cells to TRAlL-induced apoptosis. Cell Death Discov. 2016;2:16004. https://doi.org/10.1038/cddiscovery.2016.4.

82. Bagatell R, Gore L, Egorin MJ, Ho R, Heller G, Boucher N, et al. Phase pharmacokinetic and pharmacodynamic study of 17-N-allylamino-17demethoxygeldanamycin in pediatric patients with recurrent or refractory solid tumors: a pediatric oncology experimental therapeutics investigators consortium study. Clin Cancer Res. 2007;13:1783-8.

\section{Ready to submit your research? Choose BMC and benefit from:}

- fast, convenient online submission

- thorough peer review by experienced researchers in your field

- rapid publication on acceptance

- support for research data, including large and complex data types

- gold Open Access which fosters wider collaboration and increased citations - maximum visibility for your research: over $100 \mathrm{M}$ website views per year

At BMC, research is always in progress.

Learn more biomedcentral.com/submissions 